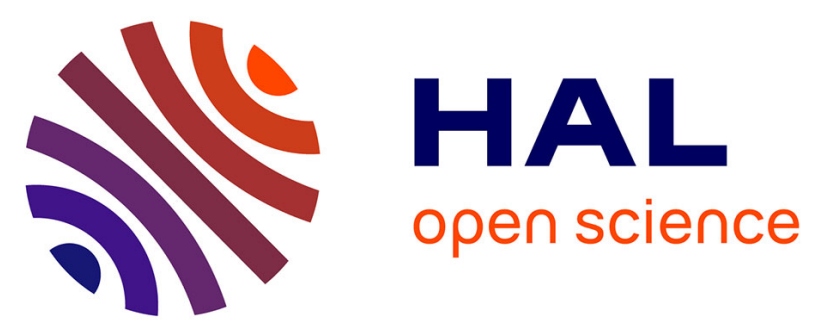

\title{
Influence of the Incorporation of CeO2 Nanoparticles on the Ion Exchange Behavior of Dodecylsulfate Doped Polypyrrole Films: Ac-Electrogravimetry Investigations
}

Chabba Benmouhoub, Jeronimo Agrisuelas, N. Benbrahim, Françoise Pillier, Claude Gabrielli, A. Kadri, Alain Pailleret, Hubert Perrot, Ozlem Sel

\section{To cite this version:}

Chabba Benmouhoub, Jeronimo Agrisuelas, N. Benbrahim, Françoise Pillier, Claude Gabrielli, et al.. Influence of the Incorporation of $\mathrm{CeO} 2$ Nanoparticles on the Ion Exchange Behavior of Dodecylsulfate Doped Polypyrrole Films: Ac-Electrogravimetry Investigations. Electrochimica Acta, 2014, 145, pp.270-280. 10.1016/j.electacta.2014.07.151 . hal-01079695

\section{HAL Id: hal-01079695 https://hal.science/hal-01079695}

Submitted on 4 Nov 2014

HAL is a multi-disciplinary open access archive for the deposit and dissemination of scientific research documents, whether they are published or not. The documents may come from teaching and research institutions in France or abroad, or from public or private research centers.
L'archive ouverte pluridisciplinaire HAL, est destinée au dépôt et à la diffusion de documents scientifiques de niveau recherche, publiés ou non, émanant des établissements d'enseignement et de recherche français ou étrangers, des laboratoires publics ou privés. 


\title{
INFLUENCE OF THE INCORPORATION OF $\mathrm{CeO}_{2}$ NANOPARTICLES ON THE ION EXCHANGE BEHAVIOR OF DODECYLSULFATE DOPED POLYPYRROLE FILMS : $A C$-ELECTROGRAVIMETRY INVESTIGATIONS
}

\author{
C. Benmouhoub ${ }^{\mathrm{a}, \mathrm{c}, \mathrm{d}}$, J. Agrisuelas ${ }^{\mathrm{b}}$, N. Benbrahim ${ }^{\mathrm{a}}$, F. Pillier ${ }^{\mathrm{c}, \mathrm{d}}$, C. Gabrielli ${ }^{\mathrm{c}, \mathrm{d}}$,

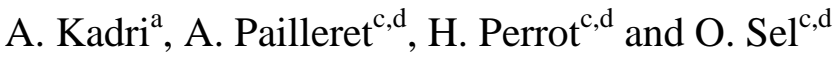 \\ ${ }^{a}$ Laboratoire de Physique et Chimie des Matériaux (LPCM), Université Mouloud \\ Mammeri, B.P. 17, 15000, Tizi-Ouzou, Algeria \\ ${ }^{b}$ Univ Valencia, Dept Quim Fis, E-46100 Valencia, Spain \\ ${ }^{c}$ Sorbonne Universités, UPMC Univ Paris VI, UMR 8235, Laboratoire Interfaces et \\ Systèmes Electrochimiques (LISE), 4, place Jussieu, case courrier 133, F-75005, Paris, \\ France \\ ${ }^{d}$ CNRS, UMR 8235, LISE, F-75005, Paris, France
}

\begin{abstract}
Cerium oxide $\left(\mathrm{CeO}_{2}\right)$ nanoparticles (NPs) possessing defined size and crystallinity have been synthesised by a co-precipitation method. The effect of several parameters, such as the nature of the solvent and the calcination process, on the crystallite size was studied by XRD, TEM and BET methods. These $\mathrm{CeO}_{2}$ nanoparticles were then incorporated in dodecylsulfate (DS) doped PPy films during their electrodeposition in potentiodynamic conditions in order to produce PPy-DS/CeO $\mathrm{CPs}_{2}$ nanocomposite thin films on gold coated quartz crystals. Simultaneous EQCM experiments revealed successful incorporation of increasing amounts of cerium oxide nanoparticles in the polypyrrole matrix during each of the consecutive CV scans. This was confirmed using FEG-SEM and EDS microanalysis.

The ion exchange phenomena occurring in the resulting nanocomposite materials were studied by ac-electrogravimetry in $\mathrm{NaCl}$ aqueous electrolyte. PPy-DS films appear to be mainly cation exchangers, independently from the incorporation of $\mathrm{CeO}_{2}$ nanoparticles (NPs) even though chloride anions in smaller amounts, and free water molecules, are
\end{abstract}


simultaneously transferred at the film/electrolytic solution interface. This study also reveals that the kinetics of $\mathrm{Cl}^{-}$ion insertion occurring at the film/electrolyte interface upon oxidation is persistently slower in $\mathrm{PPy}-\mathrm{DS} / \mathrm{CeO}_{2}$ NPs films than in PPy-DS films throughout the entire potential window of investigation. However, the relative concentration changes of $\mathrm{Cl}^{-}$ions in $\mathrm{PPy}-\mathrm{DS} / \mathrm{CeO}_{2} \mathrm{NPs}$ films is about two times greater than that occurring in pristine PPy-DS films. Such conclusion tends to demonstrate that $\mathrm{CeO}_{2} \mathrm{NPs}$ have the ability to modify the morphology of electrodeposited PPy-DS thin films as well as their subsequent permeability towards ions contained in the electrolytic solution, possibly via the perturbation of polymer chain interactions and organisation.

\section{Introduction}

Composite materials based on an electronically conducting polymer (ECP) matrix incorporating metal oxide nanoparticles constitute a fascinating class of functional materials, as shown by review articles [1]. They are potentially aimed at a vast range of applications among which one can cite protection against corrosion of iron [2], electrocatalysis [3], supercapacitors [4,5] or Li-ion batteries [6]. Besides their applications, such composite materials are also interesting from a fundamental point of view. Their complex chemical composition, the distribution of the different phases and their physicochemical interactions inside the bulk of the overall composite material make their main properties unpredictable. For example, in a recent contribution, our group showed that the conductivity of electrodeposited polypyrrole thin films undergoes opposite influences from dodecylsulfate (DS) anions and incorporated iron oxide particles [2]. More specifically, PPy-DS films were shown to possess a rather good electronic conductivity, compared to PPy films doped with other anions, as a consequence of the beneficial effect of dodecylsulfate anions. However, PPy-DS films containing iron oxide particles were found 
to have a lower conductivity that was moreover found to depend on the identity and/or crystallographic variety of the incorporated iron oxide $\left(\alpha-\mathrm{Fe}_{2} \mathrm{O}_{3}, \gamma-\mathrm{Fe}_{2} \mathrm{O}_{3}, \mathrm{Fe}_{3} \mathrm{O}_{4}\right)$ [2]. Literature also contains many reports showing that incorporation of metal or metal oxide nanomaterials in ECPs may substantially modify their well-known physico-chemical properties, besides providing new ones, which is beyond this discussion. In a nonexhaustive list, one can remind that polypyrrole/ $\mathrm{WO}_{3}$ nanomaterials based composite materials possess a rare negative permittivity and their switching frequency can be tuned with the help of particle loading. In particular, among other parameters, increased nanoparticle loading was also shown to improve the electrical conductivity, dielectric permittivity, and thermal stability of the resulting nanocomposites [7]. One should also notice that magnetite incorporation stabilizes the polaronic form of polypyrrole matrices and also preserves it from further oxidation [8] or allows production of unexpected $1 \mu \mathrm{m}$ wide stripe-like microstructures resulting from the self-assembly of magnetic components [9].

In this contribution, one of our goals was to identify a likely influence of the incorporation of cerium oxide nanoparticles on the ion transfer behaviour observed at the interface between PPy-DS/ $\mathrm{CeO}_{2}$ NPs nanocomposite materials and an aqueous electrolytic solution. During the last decades, cerium (IV) oxide $\left(\mathrm{CeO}_{2}\right)$, also named ceria, was widely applied in many fields and thus, established as one of the most interesting rare earth oxides. Numerous $\mathrm{CeO}_{2}$ synthesis procedures have been reported in literature [10-13] leading to various nanoparticle morphologies. These materials were extensively studied owing to their many distinctive characteristics and applications such as catalysts in the fuel cell technology [14], gas sensor [15], catalytic wet oxidation [16-17], oxygen storage and release [18], wastewater treatment [19] or photo-catalytic oxidation of water [20]. 


\section{Theory}

Briefly, ac-electrogravimetry consists in coupling electrochemical impedance measurements with a fast response quartz crystal microbalance (QCM) used in $a c$-mode. It allows the response in current, $\frac{\Delta E}{\Delta I}(\omega)$, electrical transfer function, and in mass, $\frac{\Delta m}{\Delta E}(\omega)$, mass-potential transfer function to be simultaneously obtained owing to a sinusoidal potential perturbation with a small amplitude $(\Delta E)$ [21-23]. The advantage of combining such transfer functions is the possibility of a fair separation of the different electrochemical processes, which involves concomitantly the mass and charge changes. In fact, at the film/electrolyte interface, the ion-exchange phenomenon is modified when a small sine wave potential perturbation, $(\Delta E)$, is applied. 
The equation describing the insertion/expulsion of species $i(i=a, c$, and $s$ for anion, cation, and solvent, respectively), characterizing the ionic transfer at the film/electrolyte interface, is the following:

$$
\frac{\Delta C_{i}}{\Delta E}(\omega)=-\frac{G_{i}}{j \omega d_{f i l m}+K_{i}}
$$

where $\omega=2 \pi f$ is the pulsation, $f$ is the potential perturbation frequency, $d_{\text {film }}$ is the film thickness, $C_{i}$ is the concentration of the species $i$ in the electroactive film and $K_{i}$ and $G_{i}$ are the partial derivatives of flux with respect to the concentration and potential respectively, $K_{i}=\left(\frac{\partial J_{i}}{\partial C_{i}}\right)_{E}$ and $G_{i}=\left(\frac{\partial J_{i}}{\partial E}\right)_{C_{i}}$, where $J_{i}$ stands for the flux of the species $i$ crossing the film/electrolyte interface. From Eq. 1, $\frac{\Delta m}{\Delta E}(\omega)$ is easily deduced in the case where three species are involved:

$$
\frac{\Delta m}{\Delta E}(\omega)=-d_{f i l m} \sum_{i=a, c, s}\left(m_{i} \frac{G_{i}}{j \omega d_{f i l m}+K_{i}}\right)
$$

where $m_{\mathrm{i}}$ is the atomic mass of the species $a, c$, or $s$. Based on the same model and according to Eq. 1, $\left.\frac{\Delta E}{\Delta I}\right)_{\text {ions }}(\omega)$ is also obtained, taking into account only the charged species transferred through the film/electrolyte interface. If one cation and one anion are involved in the electrochemical process, the following equation can be used:

$$
\left.\frac{\Delta E}{\Delta I}\right)_{\text {ions }}(\omega)=\frac{1}{j \omega d_{f i l m} F\left[\frac{G_{c}}{j \omega d_{f i l m}+K_{c}}-\frac{G_{a}}{j \omega d_{f i l m}+K_{a}}\right]}
$$

When the response of the electrochemical system is perturbed at low frequencies with a parasitic electrochemical reaction, characterized by a parasitic impedance $\left(Z_{p a r}(\omega)\right)$ 
described in equation (4), in parallel with the ionic transfer, the global electrochemical impedance (equation 5) becomes:

$$
\begin{gathered}
Z_{p a r}(\omega)=R_{p a r}+\frac{1}{j \omega C_{p a r}} \\
\frac{\Delta E}{\Delta I}(\omega)=R_{e l}+\frac{1}{\left.j \omega C_{d l}+\frac{\Delta I}{\Delta E}\right)_{\text {ions }}(\omega)+\frac{1}{Z_{p a r}(\omega)}}
\end{gathered}
$$

In Eq. $5, R_{e l}$ is the electrolyte resistance and $C_{d l}$ is the interfacial capacitance.

Another pertinent transfer function can also be simulated here, the so-called charge/potential transfer function, $\frac{\Delta q}{\Delta E}(\omega)$. This transfer function generally presents loops which correspond to the ionic transfer occurring at low frequencies. By this way, it is easier to determine the $K_{i}$ and $G_{i}$ parameters related to each species. The equation used is given by:

$$
\frac{\Delta q}{\Delta E}(\omega)=d_{f i l m} F\left[\frac{G_{c}}{j \omega d_{f i l m}+K_{c}}-\frac{G_{a}}{j \omega d_{f i l m}+K_{a}}\right]
$$

These theoretical expressions were used to simulate the experimental responses of the electrochemical impedances, $\frac{\Delta E}{\Delta I}(\omega)$, the charge/potential transfer function, $\frac{\Delta q}{\Delta E}(\omega)$, and the electrogravimetric transfer functions, $\frac{\Delta m}{\Delta E}(\omega)$. These results were compared with the experimental data which provided the key parameters, $m_{i}, K_{i}$ and $G_{i}$, to be extracted.

\section{Experimental}

\subsection{Synthesis of $\mathrm{CeO}_{2}$ nanoparticles}


The schematic diagram of the experimental procedure described hereafter is shown in Figure 1. All the chemical reagents were used without purification. The cerium (III) nitrate salt precursor $\left(\mathrm{Ce}\left(\mathrm{NO}_{3}\right)_{3}, 6 \mathrm{H}_{2} \mathrm{O}\right)$ was initially dissolved in only $\mathrm{H}_{2} \mathrm{O}$ or in a $\mathrm{C}_{2} \mathrm{H}_{5} \mathrm{OH} / \mathrm{H}_{2} \mathrm{O}$ mixture (1/1 vol.). The solution was stirred at $30^{\circ} \mathrm{C}$ and a solution of $\mathrm{NH}_{4} \mathrm{OH}$ was added. Immediately, a precipitate of $\mathrm{Ce}(\mathrm{OH})_{3}$ was formed because of its low solubility product $\left(\mathrm{K}_{\mathrm{s}}\left(\mathrm{Ce}(\mathrm{OH})_{3}=7 \cdot 10^{-21}\right)\right.$ [29], leading in a further step to a light brown coloration of the solution. Subsequently, as the $\mathrm{pH}$ was maintained at 9-9.5, the coloration of the precipitate turned purple, which is a characteristic of the oxidation of $\mathrm{Ce}(\mathrm{OH})_{3}$ into $\mathrm{Ce}(\mathrm{OH})_{4}$ by dissolved oxygen. At last, it became a light yellow suspension of $\mathrm{CeO}_{2}$. The reaction is stopped after about 1.5 hour of vigorous stirring. The obtained precipitate was centrifuged, washed with distilled $\mathrm{H}_{2} \mathrm{O}$ and ethanol alternatively three times, and then dried in a drying oven at $60^{\circ} \mathrm{C}$ for 24 hours (sometimes up to calcination at $600{ }^{\circ} \mathrm{C}$ in a furnace). In order to evaluate the influence of some of the synthesis parameters, four different powders have been compared in this work (see Table 1). Apart from $\mathrm{CeO}_{2}$ NPs of the $\underline{\mathrm{a}}$ type that were purchased from Aldrich, $\mathrm{CeO}_{2} \mathrm{NPs}$ of the $\underline{b}$ and $\underline{\mathrm{c}}$ types were synthesized in aqueous medium and in $\mathrm{C}_{2} \mathrm{H}_{5} \mathrm{OH} / \mathrm{H}_{2} \mathrm{O}$ mixture (1/1 by vol.) respectively. The latter one (c) was calcinated at $600{ }^{\circ} \mathrm{C}$ for $1 \mathrm{~h}$ and noted powder of the $\underline{\mathrm{d}}$ type. The overall chemical reaction of formation of cerium oxide in alkaline solution is as follows:

$$
2 \mathrm{Ce}\left(\mathrm{NO}_{3}\right)_{3}+\frac{1}{2} \mathrm{O}_{2}+6 \mathrm{HO}^{-} \rightarrow 2 \mathrm{CeO}_{2}+6 \mathrm{NO}_{3}^{-}+3 \mathrm{H}_{2} \mathrm{O}
$$

Let us emphasise that the liquid-phase precipitation process includes three steps: chemical reaction, nucleation and crystal growth. Generally, these three steps are fast, hence, the mixing step has a large influence on the product particle size and its distribution [29]. It is thus important to define the crystalline variety as well as an accurate estimation of the size of the resulting nanoparticles. 
3.2 Morphological Characterisation of $\mathrm{CeO}_{2}$ nanoparticles using XRD, TEM and BET

The crystallite size $\left(\mathrm{d}_{\mathrm{XRD}}\right)$ was estimated using XRD (Bruker AXS, D8 ADVANCE)

by inserting Full Width Half Maximum (FWHM) of characteristic peak (111) in the Scherrer equation [30] (see Table 1):

$$
d_{X R D}=0.9 \lambda / F W H M \cos \theta
$$

where $\lambda$ was the incident wavelength $\left(1.5406 \mathrm{~A}^{\circ}\right.$ in this study) of $\mathrm{X}$-ray and $\theta$ was the diffraction angle for the (111) plane.

The $\mathrm{CeO}_{2}$ nanoparticle diameter and morphology were determined by transmission electron microscopy (TEM, JEOL 2000Fx). For that purpose, samples for TEM were prepared by ultrasonically dispersing the $\mathrm{CeO}_{2} \mathrm{NPs}$ in ethanol, and then dropped onto carbon-coated copper grids. Corresponding TEM images and electron diffraction patterns were recorded. The average particle size $\left(\mathrm{d}_{\text {TEM }}\right)$ was determined by TEM images with a 50 particles sample.

The specific surface area of $\mathrm{CeO}_{2}$ nanoparticles $\left(\mathrm{A}\left(\mathrm{m}^{2} \cdot \mathrm{g}^{-1}\right)\right)$ was measured by nitrogen adsorption at $77.3 \mathrm{~K}$ using a Quantachrome instrument and calculated by Brunauer-Emmett-Teller equation, assuming that the $\mathrm{CeO}_{2}$ nanoparticles are spherical and non-porous [3]. The corresponding particle size $\left(\mathrm{d}_{\mathrm{BET}}\right)$ can be estimated as:

$$
d_{B E T}=6 / \rho A
$$

where $\rho$ is the density of $\mathrm{CeO}_{2}, \rho=7.28 \mathrm{~g} \cdot \mathrm{cm}^{-3}[31]$.

\subsection{Electrosynthesis and characterization of PPy-DS/ $\mathrm{CeO}_{2} \mathrm{NPs}$ nanocomposite thin films}

PPy-DS and PPy-DS/ $\mathrm{CeO}_{2}$ NPs nanocomposite films were electrodeposited from an electrolytic and colloidal aqueous solution containing freshly distilled pyrrole (Py, 0.1 mol. $\mathrm{dm}^{-3}$ ), sodium dodecylsulfate (SDS, $0.025 \mathrm{~mol} . \mathrm{dm}^{-3}$ ) and, when necessary, cerium 
oxide nanoparticles $\left(\mathrm{CeO}_{2} \mathrm{NPs}, 2 \mathrm{~g} \cdot \mathrm{dm}^{-3}\right)$ ultrasonically dispersed in the electrolytic solution prior to the proper electrosynthesis step. This latter was carried out using a BioLogic SP300 potentiostat connected to a frequencymeter (Keithley) and a lab-made oscillator by applying 10 consecutive cyclic voltammetric scans between -1.5 and 0.4 V/SSE using a $50 \mathrm{mV} . \mathrm{s}^{-1}$ scan rate. The three-electrode cell used for this purpose consists of a platinum grid as counter-electrode, a reference electrode (saturated sulphate $\mathrm{Hg}_{2} \mathrm{SO}_{4} / \mathrm{Hg}$ electrode, SSE) and a working electrode. This latter was either a working electrode made from a modified gold-patterned quartz crystal in view of simultaneous electrodeposition and EQCM experiments, or a thin film of platinum deposited on mica with the help of the sputtering technique for FEG-SEM experiments.

The morphology of the nanocomposite films was examined with a scanning electron microscope (FEG-SEM, Ultra 55 from Zeiss) coupled with EDS microanalysis.

\section{4. ac-electrogravimetry}

The electrochemical experiments were carried out in a classical three-electrode cell adapted for $a c$-electrogravimetry experiments in which the three electrodes were the same as those mentioned above for EQCM experiments.

The conditions for the electrochemical synthesis of PPy-DS and PPy-DS/CeO 2 NPs were identical to those reported above (see Part 3.3), except that, in the case of nanocomposite materials, the electrosynthesis solution contained $\mathrm{CeO}_{2}$ nanoparticles at two different concentrations, either $2 \mathrm{~g} \cdot \mathrm{dm}^{-3}$ or $5 \mathrm{~g} \cdot \mathrm{dm}^{-3}$ ) in order to evaluate the influence of the amount of cerium oxide nanoparticles incorporated in the PPy-DS matrix on the ion exchange behaviour of the resulting nanocomposite films.

As far as $a c$-electrogravimetry experiments are concerned, they were carried out in a 0.5 mol. $\mathrm{dm}^{-3} \mathrm{NaCl}$ aqueous electrolytic solution that was de-aerated prior to the 
measurements. They were performed using a lab-made $9 \mathrm{MHz}$ oscillator acting as a microbalance as well as quartz resonators (AWS, Spain) with a fundamental resonant frequency of $9 \mathrm{MHz}$. A four-channel frequency response analyzer (FRA, Solartron 1254) and a potentiostat (SOTELEM-PGSTAT) were used. The QCM was used under a dynamic regime, the modified working electrode $\left(0.2 \mathrm{~cm}^{2}\right)$ was polarized at a selected potential, and a sinusoidal small amplitude potential perturbation was superimposed. The microbalance frequency change, $\Delta \mathrm{f}_{\mathrm{m}}$, corresponding to the mass response, $\Delta \mathrm{m}$, of the modified working electrode was measured simultaneously with the $a c$ response, $\Delta \mathrm{I}$, of the electrochemical system. The resulting signals were sent to the four-channel FRA, which allowed the electrogravimetric transfer function, $\frac{\Delta m}{\Delta E}(\omega)$, and the electrochemical impedance, $\frac{\Delta E}{\Delta I}(\omega)$, to be simultaneously obtained at a given potential situated inside the potential range allowing the redox switching of the polymer film [21-23]. The third transfer function, $\frac{\Delta q}{\Delta E}(\omega)$, can be experimentally calculated by using the following equation:

$$
\frac{\Delta q}{\Delta E}(\omega)=\frac{1}{j \omega \frac{\Delta E}{\Delta I}(\omega)}
$$

\section{Results and Discussion}

\subsection{Characterization of $\mathrm{CeO}_{2}$ nanoparticles}

The crystalline variety of the $\mathrm{CeO}_{2}$ nanoparticles prepared according to different methods can be deduced from the X-ray diffraction spectra shown on Figure 2. Whatever the synthesis method, these latter exhibit lines (111), (200), (220), (311), (222) and (400) that are characteristics of $\mathrm{CeO}_{2}$, according to those of centered face cubic (CFC) fluorite structured $\mathrm{CeO}_{2}$ crystal (see JCPDS $\mathrm{N}^{\circ} 34-394$ ). Compared to the XRD patterns of a 
commercial sample, the rays appeared broader for some of those spectra because of a smaller crystallite size.

TEM was used to investigate the morphology of the synthesised nanoparticles (see Figure 3). The TEM images show a heterogeneous size and non-uniform shape for the commercial powder (a). Consequently, the size distribution is very large (from 20 to 300 $\mathrm{nm}$ ). The particles synthesised in a mixed solvent (water/ethanol: 1/1 in vol.) are smaller, homogeneous in size and spherical in shape compared to those prepared in pure water (see Figures 3b-c). Moreover, one can also observe the effect of calcination. Indeed, a higher calcination temperature and/or longer calcination duration both seem to tend to increase the particle size (see Figure 3d).

The $\mathrm{CeO}_{2}$ nanoparticle diameter was also determined from BET technique by using specific area measurement $\left(\mathrm{d}_{\mathrm{BET}}\right)$ and from direct measurement on TEM images $\left(\mathrm{d}_{\mathrm{TEM}}\right)$ and compared with that measured by XRD ( $\mathrm{d}_{\mathrm{XRD}}$, see Table 1$)$. One can observe from Table 1 that XRD, TEM and BET techniques give diameter values that are fairly close for the three different synthesis methods. This demonstrates that the $\mathrm{CeO}_{2}$ nanoparticles are primary and non-porous and also monodisperse in terms of diameter.

4.2. Electrosynthesis and composition of PPy-DS/CeO $\mathrm{NPs}_{2}$ nanocomposite films.

In the following investigations, the $\mathrm{CeO}_{2}$ nanoparticles that were used are those obtained from the synthesis method $d$ for which $d_{B E T}, d_{X R D}$ and $d_{\text {TEM }}$ are $12 \mathrm{~nm}, 10 \mathrm{~nm}$ and $12 \mathrm{~nm}$ respectively (see Table 1 ). Moreover, BET allowed the determination of a $70 \mathrm{~m}^{2} / \mathrm{g}$ specific area for those ceria nanoparticles (see Table 1).

In a first set of experiments, $\mathrm{PPy}-\mathrm{DS} / \mathrm{CeO}_{2} \mathrm{NPs}$ nanocomposite materials were electrodeposited on the gold electrode of an electrochemical quartz crystal microbalance 
(EQCM) used simultaneously as a working electrode in a usual three electrode set-up (see section 3.3 and Figure 4b). For the need of comparison, a similar experiment was carried out in the absence of cerium oxide nanoparticles (see Figure 4a). Both voltammogramms are similar as they both show the expected irreversible oxidation of the monomer known to constitute the first step of the electropolymerisation of the monomer and subsequent formation of the polymer film on the working electrode surface. One can also observe an anodic and a cathodic peak corresponding to the electroactivity of the polymer film. Intensity of both peaks increases with the number of scans, which indicates that the polymer film thickness increases as well. A similar conclusion can be drawn for the mass of the film, as observed from the curve showing the variation of the microbalance frequency. Let us remember here that according to the well-known Sauerbrey's law, an increase of the oscillation frequency of the quartz corresponds to a decrease of the mass of the deposit on the golden quartz electrode acting as a working electrode. Such electrogravimetric curves show both mass variations resulting from ions and solvent exchange occurring upon oxidation/reduction (doping/undoping) of the conducting polymer in the potential region situated between -0.5 and $-1.5 \mathrm{~V}$ vs. SSE, as well as global mass increase of the film in the potential region allowing the monomer electrochemical oxidation and polymerisation, i.e. between -0.25 and $0.4 \mathrm{~V}$ vs. SSE. The mass variation deduced from the frequency variation measured at the end of each cyclic scan, i.e. at $-1.5 \mathrm{~V}$ vs. SSE on the backward scan, was extracted and plotted as a function of each scan for both Figures $4 \mathrm{a}$ and $4 \mathrm{~b}$ (see Figure 4c). This potential value was chosen because it corresponds to a situation where the electrodeposited film is in a reduced state. By doing so, one can consider that the mass increase observed for a given scan by comparison with the previous one actually corresponds to the global mass increase of the film. By considering that the incorporation of $\mathrm{CeO}_{2}$ NPs do not alter the electrochemical deposition of the polymer, one can consider 
that the difference in the mass uptake for a given cyclic scan extracted from both figures actually correspond to the mass uptake resulting exclusively from the incorporation of NPs. This $\mathrm{CeO}_{2}$ mass uptake was plotted as a function of the number of cycles (see blue curve on Figure $4 \mathrm{c}$ ) and reaches $4 \mu \mathrm{g}$ at the ninth scan. The insert in Figure $4 \mathrm{c}$ shows a magnification of this plot for the five initial cycles. It clearly indicates that incorporation of $\mathrm{CeO}_{2} \mathrm{NPs}$ in the PPy matrix starts right from the first cycle. This possibly occurs thanks to electrostatic interactions between the oxidised and thus cationic polypyrrole film and $\mathrm{CeO}_{2} \mathrm{NPs}$ bearing negative surface charges as a consequence of adsorption of dodecylsulfate anions on their surface, according to a situation already reported in literature and encountered in the case of the incorporation of magnetite nanoparticles in polypyrrole films [32]. Taking into account an average value of $5.7 \mathrm{~nm}$ for the radius of spherical $\mathrm{CeO}_{2} \mathrm{NPs}$ ( $\mathrm{see} \mathrm{CeO}_{2} \mathrm{NPs}$ of the $\mathrm{d}$ type in Table 1) and a density value of $7.28 \mathrm{~g} / \mathrm{cm}^{-3}$ for $\mathrm{CeO}_{2}$ [31], one can estimate that 7.2 $10^{11} \mathrm{CeO}_{2}$ NPs were incorporated in the nanocomposite film in the course of the electrodeposition process illustrated in Figure $4 \mathrm{~b}$. Due to the selected film thickness, our films can be considered as acoustically thin enough and under these conditions, gravimetric response are exclusively obtained here. In other words, viscoelastic contributions can be neglected here.

\subsection{Composite morphology}

FEG-SEM observations and EDS analysis of the resulting nanocomposite films show a globular morphology bearing randomly oriented platelets (see Figure 5a), as already reported in literature for PPy films elaborated in similar experimental conditions [33]. On the surface of this complex morphology, $\mathrm{CeO}_{2}$ nanoparticle clusters (aggregates) were observed to be inhomogeneously dispersed. All these observations remain true whatever the 
$\mathrm{CeO}_{2}$ NPs concentration in the electrosynthesis solution. The EDS microanalysis confirms the presence of cerium, and thus of $\mathrm{CeO}_{2}$ nanoparticles (see Figure 5b), on and in the bulk of composite films (indeed EDS revealed the presence of ceria even in places where $\mathrm{CeO}_{2}$ nanoparticles could not be seen on the surface). Let us emphasise that the other elements detected by this analysis came from the counter-ions $(\mathrm{S}, \mathrm{O})$ and the polypyrrole skeleton $(\mathrm{C}, \mathrm{N})$.

\subsection{Film electrogeneration}

DS doped PPy films were electrogenerated in the presence or in the absence of exsitu synthesized $\mathrm{CeO}_{2}$ nanoparticles according to the electrochemical procedure reported above (see section 3.3, 3.4 and 4.2 and Figure 4). It must be emphasized that consecutive cyclic voltammograms corresponding to the electrodeposition of the films investigated in this work were very similar in every aspects, whether the concentration of cerium oxide nanoparticles in the electrodeposition solution was 0,2 , or $5 \mathrm{~g} \cdot \mathrm{dm}^{-3}$.

\subsection{Classical electrochemical characterization}

The electrochemical reactivity and stability of the resulting PPy-DS and PPy$\mathrm{DS} / \mathrm{CeO}_{2}$ NPs films were then tested after transfer in an electrolytic aqueous solution

containing $\mathrm{NaCl}\left(0.5\right.$ mol. $\left.\mathrm{dm}^{-3}\right)$. The consecutive voltammograms observed in Figure 6 show the expected pair of peaks corresponding to the above mentioned doping/undoping process of polypyrrole. There is no significant change of the shape and peak intensities of the voltammogram upon potential cycling, indicating that PPy-DS and nanocomposite PPy$\mathrm{DS} / \mathrm{CeO}_{2} \mathrm{NPs}$ films possess an electrochemical behaviour that is sufficiently stable for $a c$ electrogravimetry investigations. It has to be emphasized that such observations are also 
valid when the $\mathrm{CeO}_{2}$ NPs are incorporated during the film electrodeposition. The peak intensities are not significantly altered whatever the content of $\mathrm{CeO}_{2} \mathrm{NPs}$ in the electrodeposition solution and thus, in the resulting electrodeposited film.

\section{6. ac-electrogravimetric measurements}

The ion exchange behaviour was studied by ac-electrogravimetry in $\mathrm{NaCl}$ aqueous electrolyte $\left(0.5 \mathrm{~mol} . \mathrm{dm}^{-3}\right)$ in the active potential range between -0.6 to $-1.1 V v s$. SSE. In the following part, the interpretation procedure of $a c$-electrogravimetry data is reported for a selected potential, at $\mathrm{E}=-1.0 \mathrm{~V}$ vs. SSE.

\subsection{1. ac-electrogravimetric measurements at $\mathrm{E}=-1.0 \mathrm{~V} v s$. SSE:}

(i) Electrochemical response

Figure 7 exhibits the electrochemical impedance spectroscopy, $\frac{\Delta E}{\Delta I}(\omega)$, and the charge/potential transfer function, $\frac{\Delta q}{\Delta E}(\omega)$, data for the three different PPy films measured at $\mathrm{E}=-1.0 \mathrm{~V} v s . \mathrm{SSE}$ for PPy-DS (Figures 7a-b), PPy-DS/CeO $\mathrm{NPs}_{2}\left(2 \mathrm{~g} \cdot \mathrm{dm}^{-3}\right)$ (Figures $7 \mathrm{c}-$ d) and PPy-DS/CeO 2 NPs $\left(5\right.$ g.dm $\left.{ }^{-3}\right)$ (Figures 7e-f) films. The experimental transfer functions and the simulated data from the model (see theoretical part, eqs. 5 and 6) are reported on the same graphs. A good agreement between the two sets of data is obvious in terms of shape and frequency distribution.

The electrochemical impedance, $\frac{\Delta E}{\Delta I}(\omega)$, (see Figures $7 \mathrm{a}, \mathrm{c}$ and e) has a usual shape, when dealing with a ion-blocking electrode, from which it is difficult to easily extract information. The low frequency trend was related to a parasitic response and was simulated using equations 4 and 5. Nevertheless, considering the experimental responses 
given by these electrochemical impedances, it should be noticed that the global response seems fairly constant independent from the film composition. It should also be noted that there is no obvious part with a slope equal to $45^{\circ}$ or less in the electrochemical impedance response. Therefore, the rate limiting step is not mass transport in the film or in the solution but rather ionic transfer between the solution and the film [24]. The charge/potential transfer function, $\frac{\Delta q}{\Delta E}(\omega)$, (see Figures $7 \mathrm{~b}, \mathrm{~d}$ and $\mathrm{f}$ ) experimentally calculated through equation 7 permits to separate the ionic contribution without any possibility to identify the ionic species involved. It should be indicated here that the contribution of the parasitic reaction, occurring at low frequencies, was removed for keeping only the ionic transfer response. Two loops seem to appear in the three representations even if a fair separation is not easy to obtain. Indeed, the time constants corresponding to each ionic transfer appear to be very close to each other. At this stage, it is impossible to distinguish between anion and cation contributions and to determine which ionic species are involved. Nevertheless, the constants $K_{i}$ and $G_{i}$ were determined for two ions (see Table 2 for the $K_{i}$ values corresponding to the two ions) and were used in the following simulations.

(ii) Electrogravimetric response

Then, to clarify the contribution of the charged and also the uncharged species (i.e.

free solvent molecules), the mass/potential transfer functions, $\frac{\Delta m}{\Delta E}(\omega)$, are scrutinized. To show the evolution of the ionic transfer behavior as a function of the potential, the $\frac{\Delta m}{\Delta E}(\omega)$ responses at $-1 V$ vs. SSE of the PPy-DS (Figure 8a), PPy-DS/CeO $\mathrm{NPs}\left(2 \mathrm{~g}_{\mathrm{dm}} \mathrm{dm}^{-3}\right.$ (Figure 8c) and PPy-DS/CeO 2 NPs $\left(5\right.$ g.dm $\left.{ }^{-3}\right)$ (Figure 8e) films are shown. For all the responses, three species, sodium and chloride ions and free solvent molecules, were used in their simulations. 
The DS doped polypyrrole films have been studied earlier in our group [24]. During oxidation, the anions were inserted in the film, whereas cations and solvent were expelled during oxidation. The kinetic constants of cations were the highest, followed by those of free solvent molecules and the anions contributed at low frequencies. As far as the PPy-DS films of the present study are concerned, the time constants of cations, solvent and anions are very close to each other and the different values obtained here do not correspond exactly with those reported previously. This could be attributed to the differences in the film preparation, specifically to the SDS concentration and potential range used during the potentiodynamic electrogeneration of the present PPy-DS films.

It should be noted that the contributions of the cation, the anion and the free solvent molecules are not perfectly separated as it can be seen in Figure 8. To solve this problem, partial transfer functions, $\left.\frac{\Delta m}{\Delta E}\right)_{a s}(\omega)$ (corresponding to anion and solvent contribution) and $\left.\frac{\Delta m}{\Delta E}\right)_{c s}(\omega)$ (corresponding to cation and solvent contribution), were calculated and simulated to separate these contributions as it was already described elsewhere [24]. This method allows the contribution of one charged species to be removed; for example either a cation or an anion in case of cation, anion and free solvent contributions. Moreover, the response of the cation or of the anion is amplified in the resulting partial mass/potential transfer functions. This permits to a better separation between the charged species contribution and that of the free solvent. Here, only the anion/solvent mass-potentiel transfer functions, $\left.\frac{\Delta m}{\Delta E}\right)_{a s}(\omega)$, were shown in Figures $8 \mathrm{~b}, \mathrm{~d}$ and $\mathrm{f}$ for the three different films. The sodium contribution was removed from the global mass-potential transfer function, $\left.\frac{\Delta m}{\Delta E}\right)(\omega)$. For the three films, a high frequency loop is observed in the third 
quadrant indicating a motion in the same direction as sodium ions and corresponding to the free solvent. At low frequency appears a small loop, located in the fourth quadrant, associated to chloride ions with an opposite flux compared with cations and free solvent motion for a same potential change. This approach is the only way to clearly demonstrate the anion contribution since a minor loop is observed in the total $\left.\frac{\Delta m}{\Delta E}\right)(\omega)$ diagram. For the water response, the semi-circle diameter is smaller for the PPy-DS compared to the two composite films, which indicates a greater contribution of water in this case.

At -1 $V$ vs. SSE, using the parameters, $K_{c}, K_{a}, G_{c}$ and $G_{a}$ obtained from the previous electrochemical simulations (Figure 7 and Table 2), the atomic weight of the three mentioned species, $m_{c}, m_{a}$ and $m_{s}$, the last two unknown parameters, $K_{s}$ and $G_{\mathrm{s}}$, associated to the free solvent transfer, can be estimated. For the three different films, at this potential, the ac-electrogravimetric response is located in the third quadrant: $\mathrm{H}_{2} \mathrm{O}$ contribution appears at high frequencies, $\mathrm{Na}^{+}$for the intermediate frequencies and $\mathrm{Cl}^{-}$at low frequencies. The values of the key parameters $K_{i}$ and $G_{i}$, for the three species, are listed in Table 2. The values of $K_{i}$ are coherent with the rate of transfer associated to the three species i.e. $K_{s}>K_{c}>K_{a}$. In the case of the PPy-DS film, the three $K_{i}$ values are higher compared with those obtained with the two other films containing $\mathrm{CeO}_{2} \mathrm{NPs}$. This result demonstrates qualitatively different ion-exchange behaviours between PPy-DS and PPy$\mathrm{DS} / \mathrm{CeO}_{2} \mathrm{NPs}$ films. Another interesting parameter, the ionic transfer resistance, $R t_{i}$, can also be estimated using the $G_{i}$ values and the relation $R t_{i}=\frac{1}{F G_{i}}$. For all the films, water transfer is easy as $R t_{\mathrm{H}_{2} \mathrm{O}}$ show the smallest values. The chloride transfer, characterized by $R t_{\mathrm{Cl}^{-}}$, presents higher values, especially in the case of the composite films. Thus, chloride transfer is more difficult and slower with the composite layers. Another interesting variable 
named concentration/potential transfer function $\left.\left(\frac{\Delta C_{i}}{\Delta E}\right)_{\omega \rightarrow 0}\right)$ can be described as the concentration change related to the individual species, following a potential step. This quantity can be estimated through the following relation $\left.\frac{\Delta C_{i}}{\Delta E}\right)_{\omega \rightarrow 0}=-\frac{G_{i}}{K_{i}}$. According to Table 2, in the case of PPy-DS, the water contribution is predominant which is followed by the sodium contribution and finally, only a small part is due to chloride ions. In the case of the two PPy-DS/CeO 2 NPs films, this ratio remains constant for $\mathrm{Cl}^{-}$, it decreases slightly for $\mathrm{Na}^{+}$and becomes more important for $\mathrm{H}_{2} \mathrm{O}$. A more porous structure can be pictured in the case of composite films, which favors the water transfer after a potential jump.

\subsubsection{The changes of key parameters over the potential applied}

For all the potential values selected in the active range, the two key parameters $K_{i}$ and $R t_{i}$ were determined according to the procedure described above and shown for the measurements at -1 Vvs. SSE. These values are presented in Figure 9.

For the sodium contribution (see Figure 9a), two domains can be distinguished in terms of transfer rate. In the cathodic region, i.e. below $-1 \mathrm{~V}$ vs. SSE, $\mathrm{Na}^{+}$is faster for the PPy-DS films while it is faster in the anodic region, i.e. above $-0.9 \mathrm{~V}$ vs. SSE, for the composite films. In the case of $\mathrm{Cl}^{-}$anions, the kinetics of transfer is independent of the potential and remains faster in the case of the PPy-DS film (see Figure 9b). For the free solvent, the plot of the influence of potential on $\mathrm{K}_{\mathrm{s}}$ values shows bell-shaped curves for the composite materials and decreasing trend for the PPy-DS film (Figure 9c).

There are also two distinct domains in the charge transfer resistance values for $\mathrm{Na}^{+}$ ions (see Figure 9d). In the cathodic range situated below $-0.8 \mathrm{~V}$ vs. SSE, $\mathrm{Na}^{+}$transfer is rather easier for the PPy-DS films than in the anodic region situated above this same value. 
When $\mathrm{CeO}_{2}$ particles are present in the films (Figure 9d), the opposite behaviour is observed with a threshold potential of $-0.85 \mathrm{~V}$ vs. SSE. The chloride ion transfer presents higher values in the case of the composite films. This is more pronounced in the cathodic region situated below $-0.8 \mathrm{~V}$ vs. SSE. Thus, chloride transfer is more difficult and slower in the composite layers (Figures $9 \mathrm{~b}$ and e).

4.6.3. Evolution of the relative concentration, $\Delta C_{i}$, of each species as a function of the applied potential.

To quantify the role of each species, $\left.\frac{\Delta C_{i}}{\Delta E}\right|_{\omega \rightarrow 0}$ has been estimated as a function of the potential. It was shown that at low frequencies, $\left.\frac{\Delta C_{i}}{\Delta E}\right|_{\omega \rightarrow 0}$ becomes $\left.\frac{\Delta C_{i}}{\Delta E}\right|_{\omega \rightarrow 0}=-\frac{G_{i}}{K_{i}}$ ( $K_{i}$ and $G_{i}$ values are obtained from simulation of the data shown in Figures 7 and 8) [2123]. The integration of the $\left.\frac{\Delta C_{i}}{\Delta E}\right|_{\omega \rightarrow 0}$ against potential gives the insertion isotherm. Figure 10 presents the relative concentration change, $\Delta C_{\mathrm{Na}^{+}}, \Delta C_{\mathrm{Cl}^{-}}$and $\Delta C_{\mathrm{H}_{2} \mathrm{O}}$, for $\mathrm{Na}^{+}, \mathrm{Cl}^{-}$and $\mathrm{H}_{2} \mathrm{O}$, respectively.

The $\Delta C_{N a^{+}}$values of the PPy-DS films with and without incorporation of $\mathrm{CeO}_{2}$ nanoparticles do not show a remarkable difference. $C_{\mathrm{Na}^{+}}$decreases, indicating the expulsion of the $\mathrm{Na}^{+}$ions during oxidation (Figure 10a). Although slightly faster transfer of the cations at the film/electrolyte interface was observed, when $\mathrm{CeO}_{2} \mathrm{NPs}$ are present in PPy-DS films, one can observe that at $\mathrm{E}=-0.8 \mathrm{~V} v s$. SSE for example, $\Delta C_{\mathrm{Na}^{+}}$becomes very close for the three investigated materials. Total $\mathrm{H}_{2} \mathrm{O}$ amount involved indirectly in the 
charge compensation process is magnified when the PPy-DS films contain $\mathrm{CeO}_{2}$ nanoparticles. The water content increases as a function of the $\mathrm{CeO}_{2} \mathrm{NPs}$ content in the PPy-DS/CeO 2 NPs films (Figure 10b). This is possibly due to the increased porous volume in the conducting polymer as a result of the added $\mathrm{CeO}_{2}$ nanoparticles. Interestingly, the $\Delta C_{\mathrm{Cl}^{-}}$values of PPy-DS/CeO 2 NPs $\left(2 \mathrm{~g} \cdot \mathrm{dm}^{-3}\right)$ and PPy-DS/CeO $2\left(5 \mathrm{~g} \cdot \mathrm{dm}^{-3}\right)$ films are about three times greater than that of PPy-DS films (Figure 10c). The kinetic study discussed above showed that the $\mathrm{Cl}^{-}$ions in PPy-DS/CeO 2 NPs films at the film/electrolyte interface are slower compared with pristine PPy-DS films. Although the kinetics is slower in the presence of $\mathrm{CeO}_{2}$ nanoparticles, the total amount of the $\mathrm{Cl}^{-}$ions inserted during oxidation are substantially higher than for pristine PPy-DS films.

Further experiments are currently underway to gain further information about the reasons explaining why PPy-DS/CeO $\mathrm{CPs}_{2}$ composite films possess a permeability to water and chloride anions different from that observed for pristine PPy-DS films. One possible explanation can be based on a predictable effect (although poorly characterised at the present stage of our investigations) of cerium oxide nanoparticles incorporation on the porosity of such films. Another interesting issue is the electrocatalytic behaviour of cerium oxide nanoparticles towards water oxidation [20] resulting in water consumption and protons production that may enhance water and chloride exchanges observed at rather anodic potentials for PPy-DS/CeO 2 NPs composite films.

\section{Conclusion}

In this contribution, $\mathrm{PPy}-\mathrm{DS} / \mathrm{CeO}_{2} \mathrm{NPs}$ nanocomposite films were electrogenerated successfully, as evidenced from cyclic electrogravimetry, SEM-FEG and EDS experiments, from electrolytic and colloidal aqueous solutions containing $\mathrm{CeO}_{2}$ nanoparticles 
synthesised ex-situ. The incorporation of cerium oxide nanoparticles was shown to affect substantially the ion exchange behaviour of dodecylsulfate doped polypyrrole films upon electrochemical doping/undoping, as revealed from ac-electrogravimetry experiments, but not its electrochemical behavior as observed from cyclic voltammetry technique used for the electrodeposition step or after transfer in a blank electrolytic and aqueous solution. In this latter case, whatever the $\mathrm{CeO}_{2}$ nanoparticles content is, upon electrochemical oxidation of the film, chloride anions and sodium cations were actually found to be inserted in and expelled out of the film, respectively. In addition, free water molecules were found to be systematically expelled (as sodium cations) upon oxidation of the film (except for rather anodic potentials in the absence of ceria nanoparticles in the film). The main influence of the presence of cerium oxide nanoparticles was observed on the transfer rates of the exchanged species. As the cerium oxide nanoparticles content increases in the PPy-DS films, sodium cations and chloride anions were found to be exchanged much faster and much slower respectively. Finally, chloride anions were found to be exchanged in higher amounts in the presence of $\mathrm{CeO}_{2}$ nanoparticles than in their absence. All these observations tend to indicate that the incorporation of cerium oxide nanoparticles increases the permeability of PPy-DS thin films towards chloride anions in terms of quantities but not from a kinetic aspect.

\section{Acknowledgements}

C. Benmouhoub acknowledges sincerely the Algerian government for having delivered to her a 18 month PNE-type scholarship. 


\section{References}

[1] D.W. Hatchett, M. Josowicz, Composites of Intrinsically Conducting Polymers as Sensing Nanomaterials, Chem. Rev. 108 (2008) 746.

[2] A. Pailleret, N.T.L. Hien, D.T.M. Thanh, C. Deslouis, Surface reactivity of polypyrrole/iron-oxide nanoparticles: electrochemical and CS-AFM investigations, J. Solid State Electrochem. 11 (2007) 1013.

[3] J.F. Rivera, C. Bucher, E. Saint-Aman, B.L. Rivas, M.C. Aguirre, J. Sanchez, I. PignotPaintrand, J.C. Moutet, Removal of arsenite by coupled electrocatalytic oxidation at polymer-ruthenium oxide nanocomposite and polymer-assisted liquid phase retention, Appl. Catal. B, 129 (2013) 130.

[4] R.K. Sharma, L. Zhai, Multiwall carbon nanotube supported poly(3,4ethylenedioxythiophene)/ manganese oxide nano-composite electrode for super-capacitors, Electrochim. Acta, 54 (2009) 7148.

[5] M. Jin, G. Han, Y. Chang, H. Zhao, H. Zhang, Flexible electrodes based on polypyrrole/manganese dioxide/polypropylene fibrous membrane composite for supercapacitor, Electrochim. Acta 56 (2011) 9838.

[6] I. Boyano, J.A. Blazquez, I. De Meatza, M. Bengoechea, O. Miguel, H. Grande, Y.

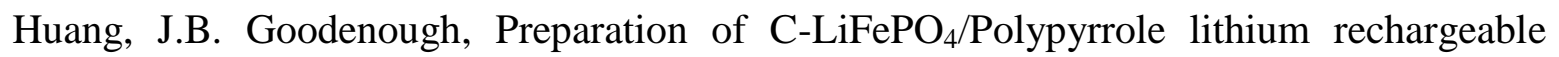
cathode by consecutive potential steps electrodeposition, Journal of Power Sources 195 (2010) 5351-5359.

[7] J. Zhu, S. Wei, L. Zhang, Y. Mao, J. Ryu, P. Mavinakuli, A.B. Karki, D.P. Young, Z. Guo, Conductive Polypyrrole/Tungsten Oxide Metacomposites with Negative Permittivity, J. Phys. Chem. C, 114 (2010) 16335-16342. 
[8] P. Montoya, F. Jaramilloa, J. Calderóna, S.I. Córdoba de Torresi, R.M. Torresi, Evidence of redox interactions between polypyrrole and $\mathrm{Fe}_{3} \mathrm{O}_{4}$ in polypyrrole- $-\mathrm{Fe}_{3} \mathrm{O}_{4}$ composite films, Electrochimica Acta, 55 (2010) 6116-6122.

[9] C. Janáky, C. Visy, O. Berkesi, E. Tombácz, Conducting Polymer-Based Electrode with Magnetic Behavior: Electrochemical Synthesis of Poly(3-thiophene-acetic-acid)/Magnetite Nanocomposite Thin Layers, J. Phys. Chem. C, 113 (2009) 1352-1358.

[10] Q. Wu, F. Zhang, P. Xiao, H. Tao, X. Wang, Z. Hu, Y. Lü, Great Influence of Anions for Controllable Synthesis of $\mathrm{CeO}_{2}$ Nanostructures: From Nanorods to Nanocubes, J. Phys. Chem. C, 112 (2008) 17076.

[11] N.J. Lawrence, J.R. Brewer, L. Wang, T.-S. Wu, J. Wells-Kingsbury, M.M. Ihrig, G. Wang, Y.-L. Soo, W.-N. Mei, C.L. Cheung, Defect Engineering in Cubic Cerium Oxide Nanostructures for Catalytic Oxidation, Nano Lett. , 11 (2011) 2666.

[12] X. Liang, J. Xiao, B. Chen, Y. Li, Catalytically Stable and Active $\mathrm{CeO}_{2}$ Mesoporous Spheres, Inorg. Chem., 49 (2010) 8188.

[13] C. Slostowski, S. Marre, O. Babot, T. Toupance, C. Aymonier, Near- and Supercritical Alcohols as Solvents and Surface Modifiers for the Continuous Synthesis of Cerium Oxide Nanoparticles, Langmuir, 28 (2012) 16656.

[14] J. Kaspar, P. Fornasiero, N. Hickey, Automotive catalytic converters: current status and some perspectives, Catal. Today 77 (2003) 419.

[15] N. Izu, W. Shin, N. Murayama, S. Kanzaki, Resistive oxygen gas sensors based on $\mathrm{CeO}_{2}$ fine powder prepared using mist pyrolysis, Sens. Actuator B-Chem. 87 (2002) 95 .

[16] A. Trovarrelli, C. De Leitenberg, M. Boaro, G. Dolcetti, The utilization of ceria in industrial catalysis, Catal. Today 50 (1999) 353.

[17] F. Larachi, J. Pierre, A. Adnot, A. Bernis, Ce 3d XPS study of composite $\mathrm{Ce}_{\mathrm{x}} \mathrm{Mn}_{1-\mathrm{x}} \mathrm{O}_{2-\mathrm{y}}$ wet oxidation catalysts, Appl. Surf. Sci. 195 (2002) 236. 
[18] H. Imagawa, A. Suda, K. Yamamura, S. Sun, Monodisperse $\mathrm{CeO}_{2}$ Nanoparticles and Their Oxygen Storage and Release Properties, J. Phys. Chem. C, 115 (2011) 1740.

[19] H. Xiao, Z. Ai, L. Zhang, Nonaqueous Sol-Gel Synthesized Hierarchical $\mathrm{CeO}_{2}$ Nanocrystal Microspheres as Novel, Adsorbents for Wastewater Treatment, J. Phys. Chem. C, 113 (2009) 16625.

[20] G.R. Bamwenda, H.Arakawa, Cerium dioxide as a photocatalyst for water decomposition to $\mathrm{O}(2)$ in the presence of $\mathrm{Ce}(\mathrm{aq})(4+)$ and $\mathrm{Fe}(\mathrm{aq})(3+)$ species, J. Mol. Catal. A $161(2000) 105$.

[21] L.T.T. Kim, C. Gabrielli, A. Pailleret, H. Perrot, Correlation between ion-exchange properties and swelling/shrinking processes in hexasulfonated calix[6]arene doped polypyrrole films: ac-electrogravimetry and electrochemical atomic force microscopy investigations, Electrochim. Acta 56 (2011) 3516.

[22] L.T.T. Kim, C. Gabrielli, A. Pailleret, H. Perrot, Ions/Solvent Exchanges and Electromechanical Processes in Hexasulfonated Calix[6]Arene Doped Polypyrrole Films: Towards a Relaxation Mechanism, Electrochem. Solid-State Lett. 14 (2011) F9.

[23] C. Gabrielli, J.J. Garcia-Jareno, M. Keddam, H. Perrot, F. Vicente, Acelectrogravimetry study of electroactive thin films. I. Application to Prussian Blue J. Phys. Chem. B 106 (2002) 3182.

[24] C. Gabrielli, J.J. Garcia-Jareno, M. Keddam, H. Perrot, F. Vicente, Acelectrogravimetry study of electroactive thin films. II. Application to Polypyrrole J. Phys. Chem. B 106 (2002) 3192.

[25] C. Gabrielli, H. Perrot, in: M. Schlesinger (Ed.), Modern Aspects of Electrochemistry No.44, Modeling and Numerical Simulations II, Springer, 2009, Chap. 5. 


\section{b)}

[26] O. Sel, L. To Thi Kim, C. Debiemme-Chouvy, C. Gabrielli, C. Laberty-Robert, H. Perrot, C. Sanchez, Proton Insertion Properties in a Hybrid Membrane/Conducting Polymer Bilayer Investigated by AC Electrogravimetry, J. Electrochem. Soc. 157 (2010) F69.

[27] L. To Thi Kim, C. Debiemme-Chouvy, C. Gabrielli, H. Perrot, Redox Switching of Heteropolyanions Entrapped in Polypyrrole Films Investigated by ac-Electrogravimetry, Langmuir 28 (2012) 13746.

[28] O. Sel, L. To Thi Kim, C. Debiemme-Chouvy, C. Gabrielli, C. Laberty-Robert, H. Perrot, Determination of the Diffusion Coefficient of Protons in Nafion Thin Films by acElectrogravimetry, Langmuir 29 (2013) 13665-13660.

[29] X.D. Zhou, W. Huebner, H.U. Anderson, Processing of nanometer-scale $\mathrm{CeO}_{2}$ particles, Chem. Mater. 15(2) (2003) 378-382.

[30] R. Jenkins, R. L. Snyder, X-Ray Powder Diffractometry, Ed. Wiley-Interscience, 1996, 89-91.

[31] S. Tsunekawa, T. Fukuda, A. Kasuya, Blue shift in ultraviolet absorption spectra of monodisperse $\mathrm{CeO}_{2-x}$ nanoparticles, J. Appl. Phys. 87(3) (2000) 1318-1321.

[32] C. Janáky, B. Endrődi, O. Berkesi, C. Visy, Visible-light-Enhanced electrocatalytic activity of a polypyrrole/magnetite hybrid electrode toward the reduction of dissolved dioxygen, J. Phys. CHem. C, 114 (2010) 19338-19344.

[33] D. Kowalski, M. Ueda, T. Ohtsuka, Corrosion protection of steel by bi-layered polypyrrole doped with molybdophosphate and naphthalenedisulfonate anions, Corros. Sci. 49 (2007) 1635-1644. 


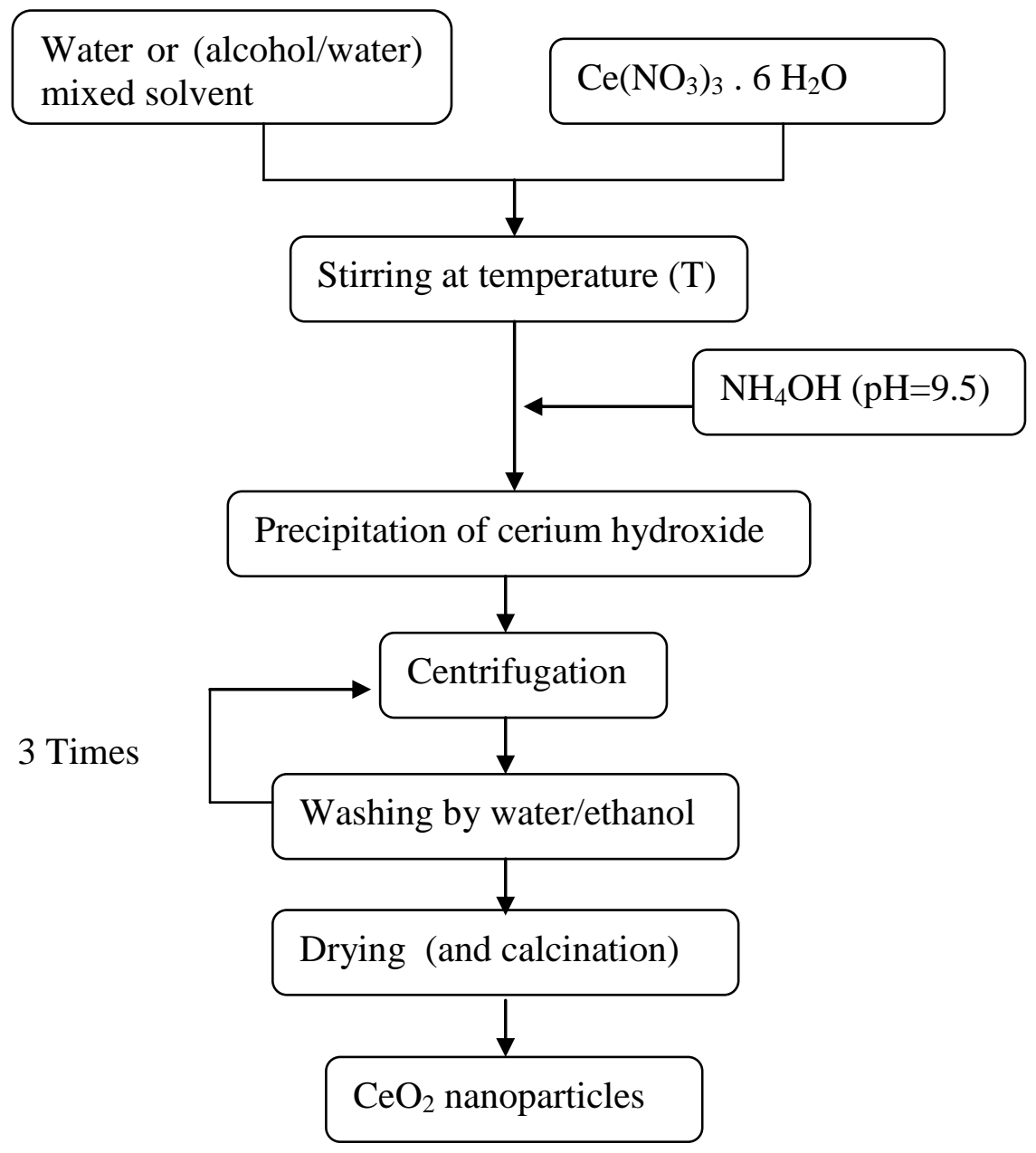

Figure 1: Synoptic scheme of $\mathrm{CeO}_{2}$ nanoparticles synthesis. 


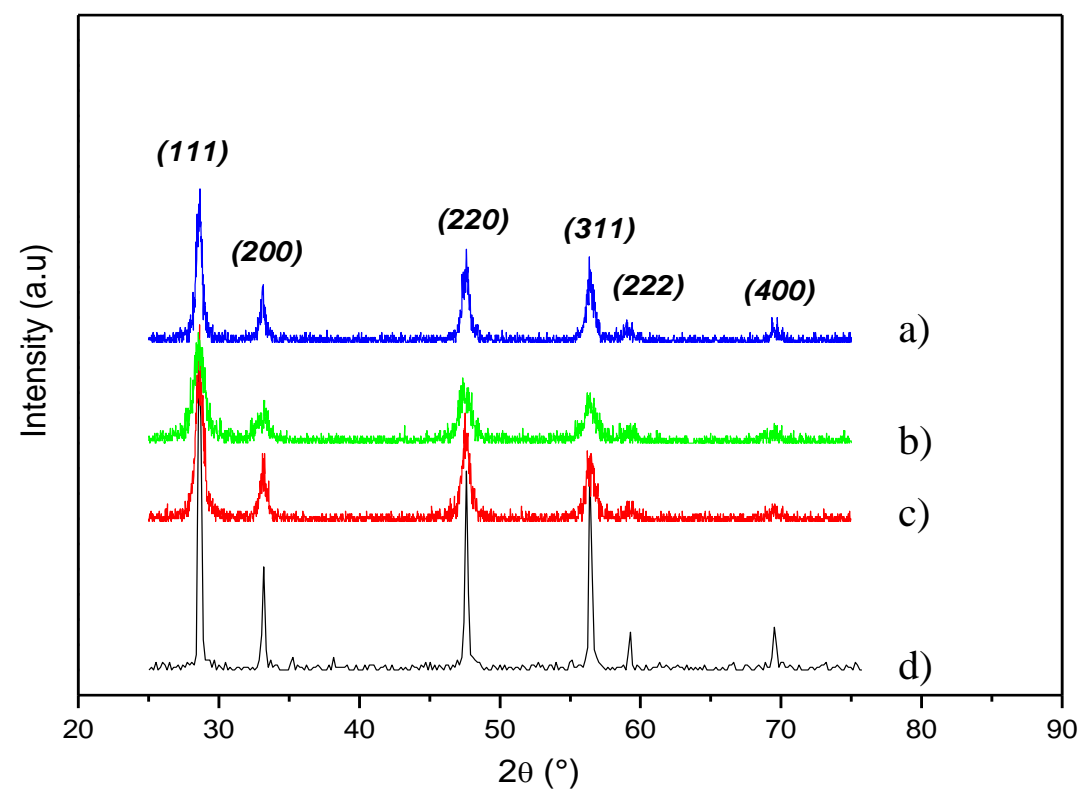

Figure 2: XRD diffraction patterns of ceria nanoparticules $\left(\mathrm{CeO}_{2}\right)$ : a) commercial sample, b) prepared in water at $\left.30^{\circ} \mathrm{C}, \mathrm{c}\right)$ prepared in water/ethanol $(1 / 1$ by vol. $)$ at $\left.30^{\circ} \mathrm{C}, \mathrm{d}\right)$ as $(\mathrm{c})$ then calcinated at $600^{\circ} \mathrm{C}$ for $1 \mathrm{~h}$. 

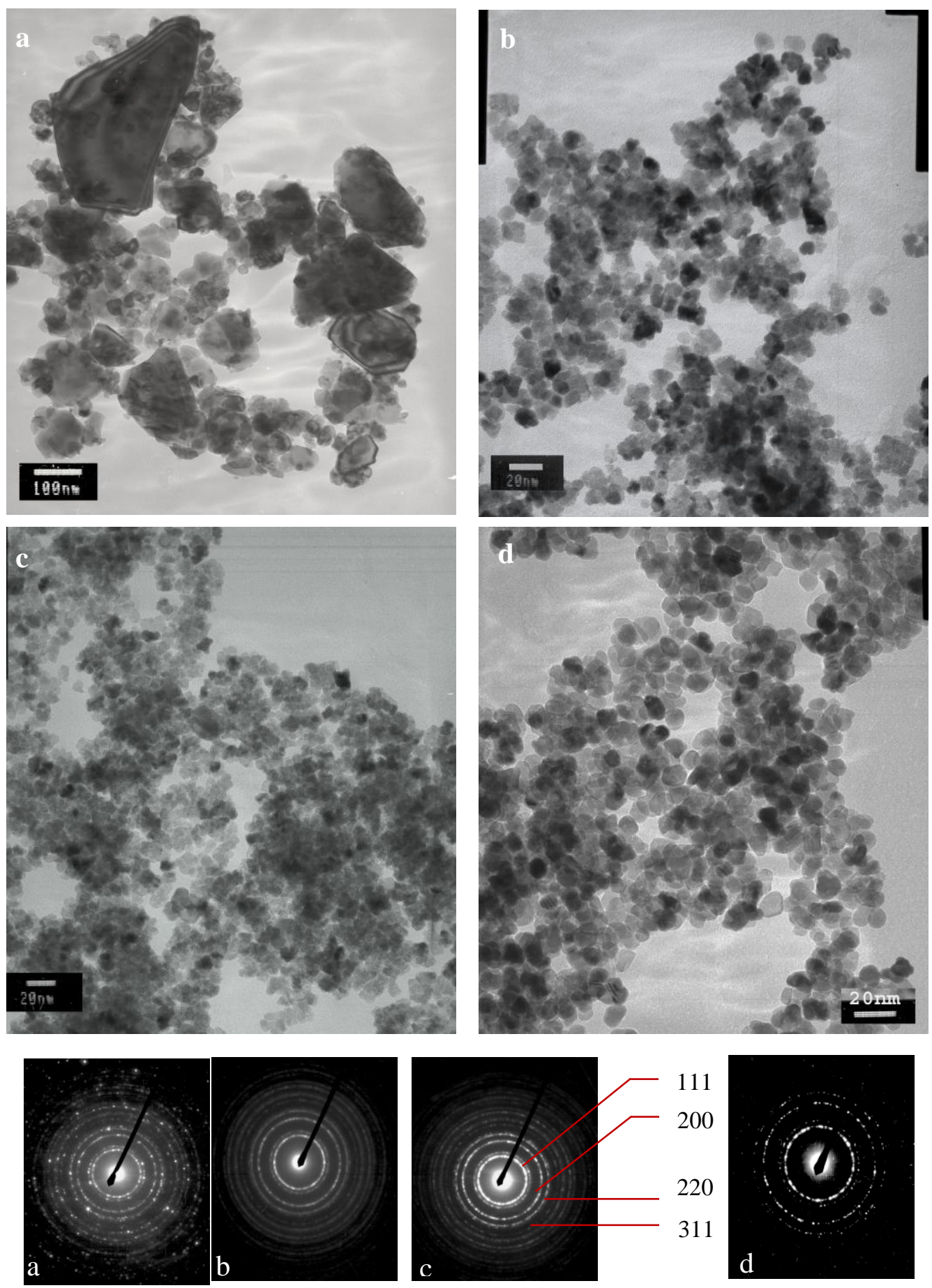

Figure 3: TEM images and corresponding electronic diffractions of a, b, c and d-type $\mathrm{CeO}_{2}$ nanoparticles. 
a)

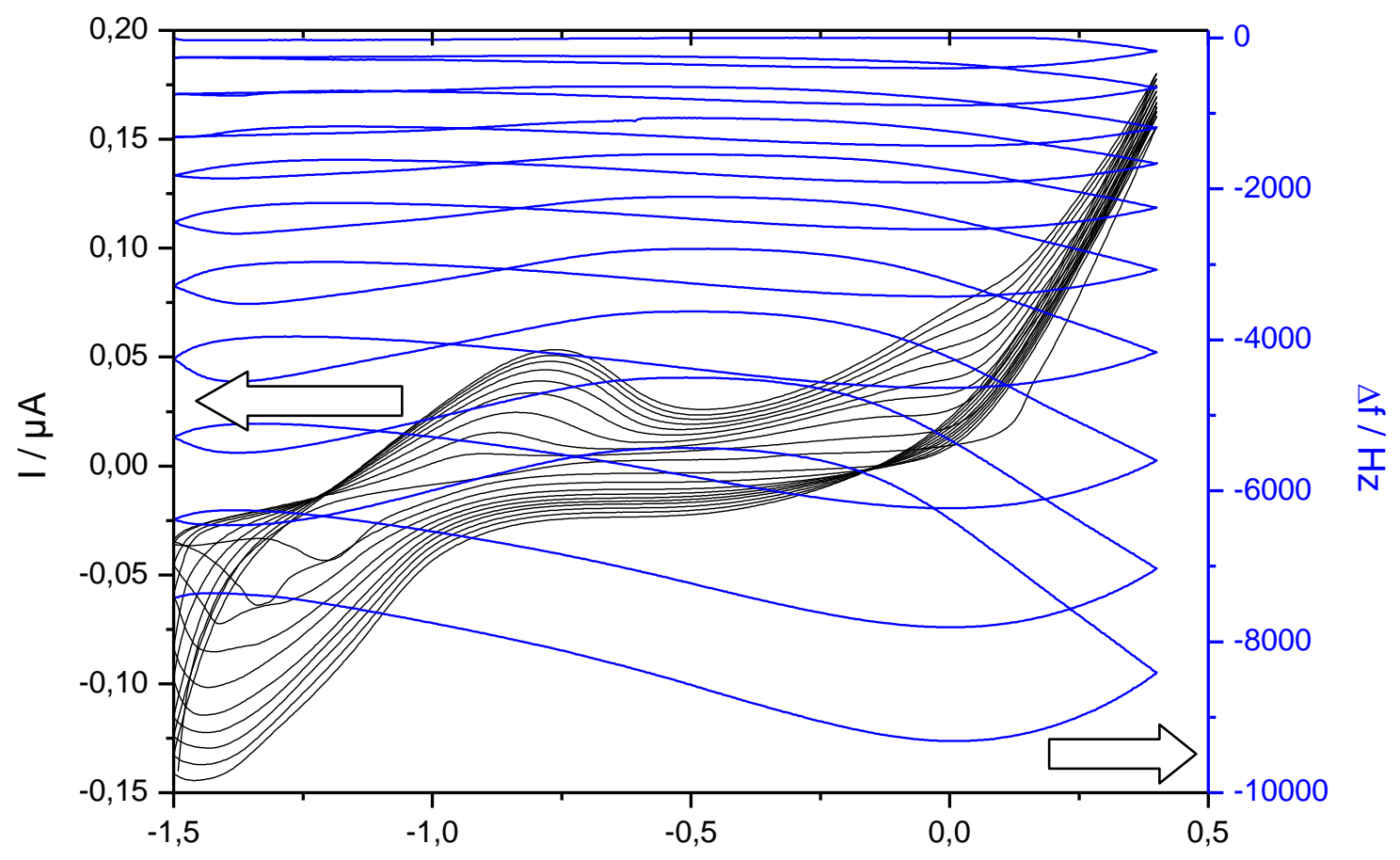

E / V vs.SSE

b)

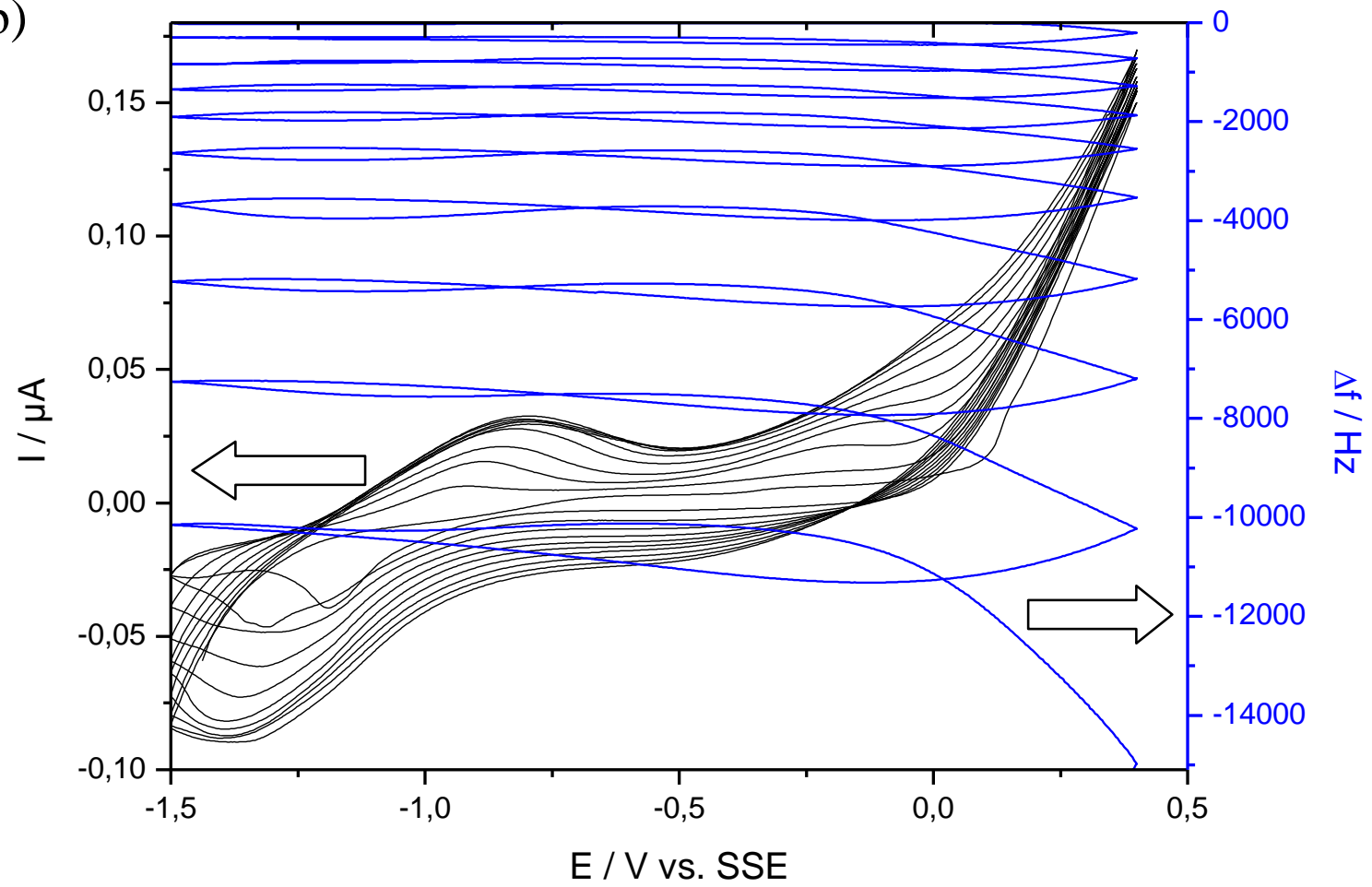


c)

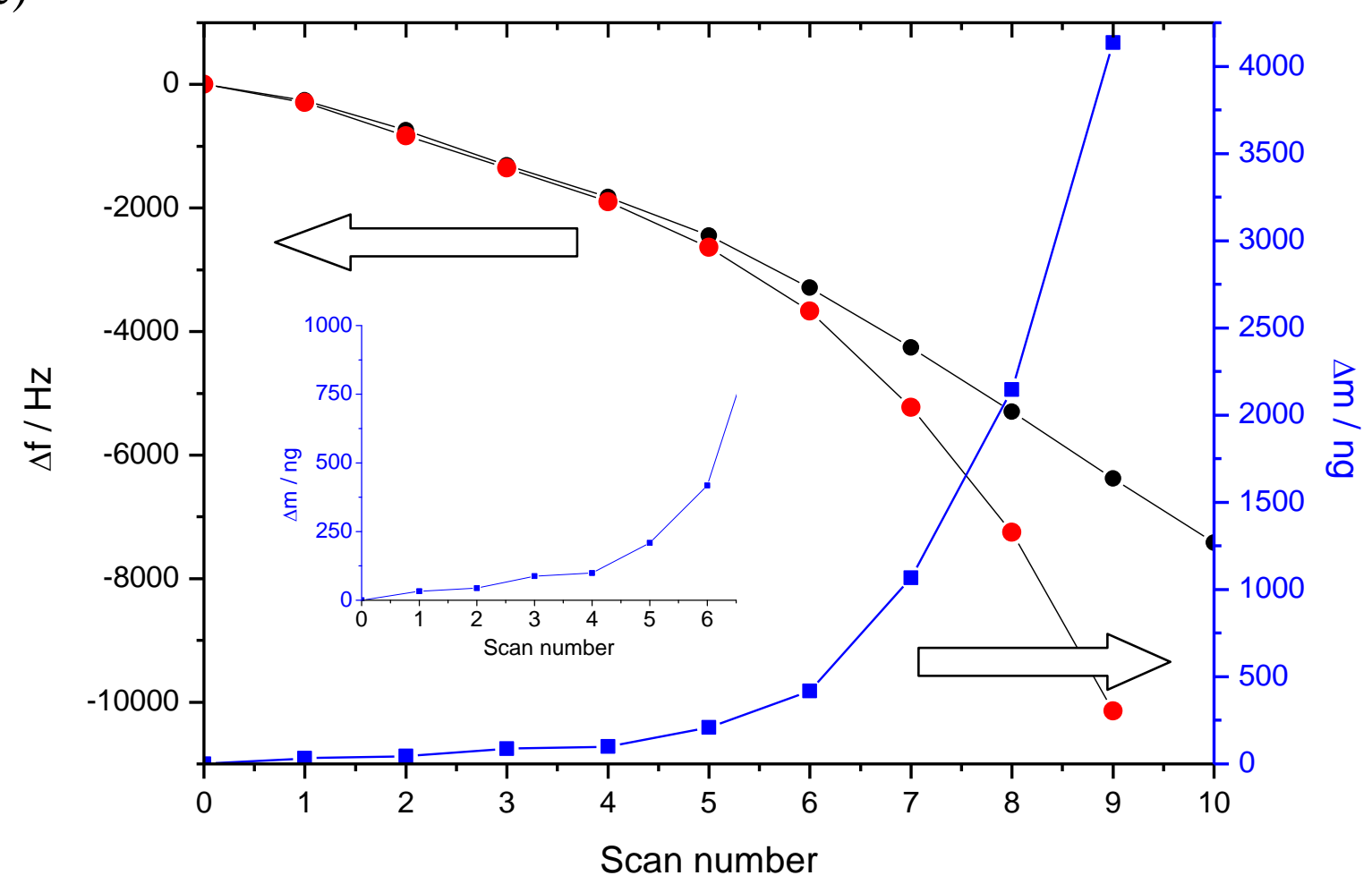

Figure $4:$ a,b) cyclic voltammetry (black curve) and EQCM response (blue curve) obtained simultaneously in the course of the electrodeposition of PPy-DS films on a gold coated quartz a) in the absence, b) in the presence of $\mathrm{CeO}_{2}$ nanoparticles $\left(2 \mathrm{~g} \cdot \mathrm{dm}^{-3}\right)$, in an aqueous electrolytic solutions containing Py monomer $\left(0.1 \mathrm{~mol} . \mathrm{dm}^{-3}\right)$ and sodium dodecylsulfate $\left(0.025\right.$ mol. $\left.\mathrm{dm}^{-3}\right)$ during 10 scans. Scan rate $\left.: 50 \mathrm{mV}^{-1} \mathrm{~s}^{-1} . \mathrm{c}\right)$ frequency variation (black and red dots) and mass variation difference (blue dots) all measured at the end of each cyclic voltammetry scan (-1.5 V vs. SSE) and extracted from Figures 4a,b. Mass variation difference is calculated from the difference between the mass variation measured during the electrodeposition of PPy-DS film in the presence of $\mathrm{CeO}_{2} \mathrm{NPs}$ (red dots) and that measured in the absence of $\mathrm{CeO}_{2} \mathrm{NPs}$ (black dots) and is attributed in a first approximation to the uptake of $\mathrm{CeO}_{2} \mathrm{NPs}$ only. 

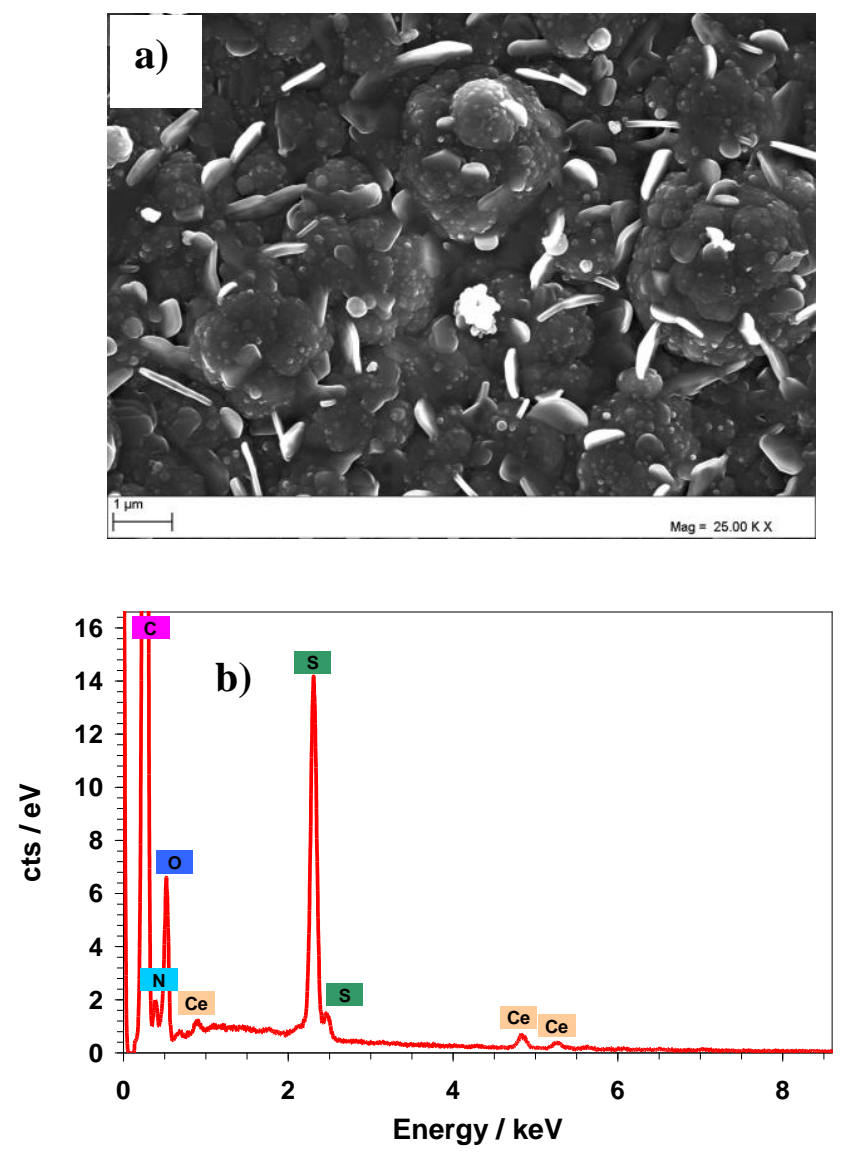

Figure 5: a) SEM image and b) EDS spectrum of PPy-DS/CeO $\mathrm{NPs}_{2}$ nanocomposite films electrodeposited from an electrolytic and colloidal aqueous solution containing SDS (0.025 mol.dm $\left.{ }^{-3}\right), \mathrm{CeO}_{2}$ NPs $\left(1\right.$ g.dm $\left.{ }^{-3}\right)$ and pyrrole $\left(0.1\right.$ mol.dm $\left.{ }^{-3}\right)$. 


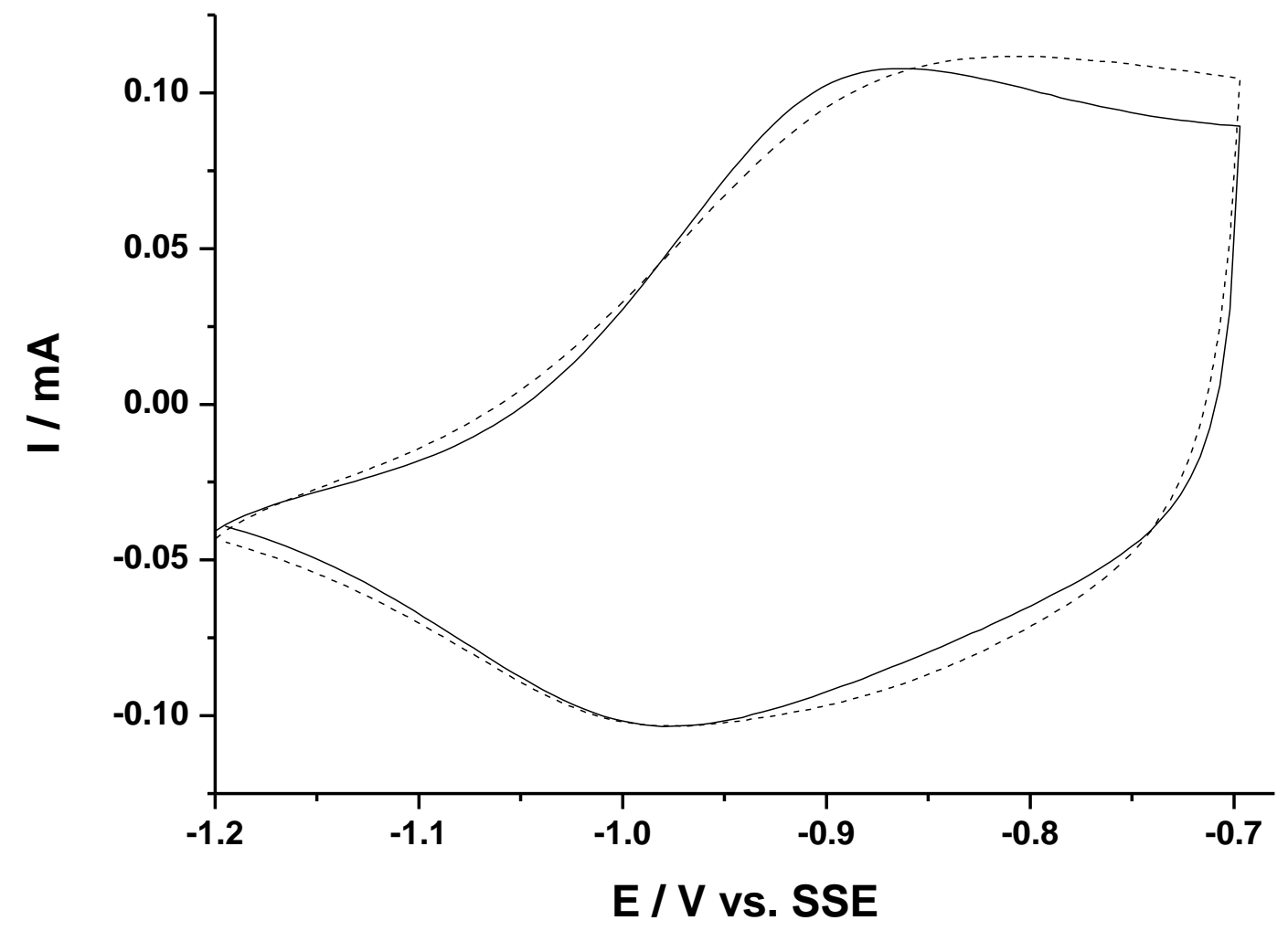

Figure 6: Consecutive cyclic voltammograms (solid line $: 1^{\text {st }}$ scan, dash line $: 15^{\text {th }}$ scan) obtained for a working electrode modified with a PPy-DS/CeO ${ }_{2}$ NPs nanocomposite thin film doped with DS anions in an aqueous electrolytic solution containing $\mathrm{NaCl}(0.5$ mol. $\left.\mathrm{dm}^{-3}\right)$. Working electrode : gold coated quartz crystal adapted for $a c$-electrogravimetry experiments, counter-electrode: platinum grid, reference electrode: SSE and scan rate: 50 $\mathrm{mV} \cdot \mathrm{s}^{-1}$. 


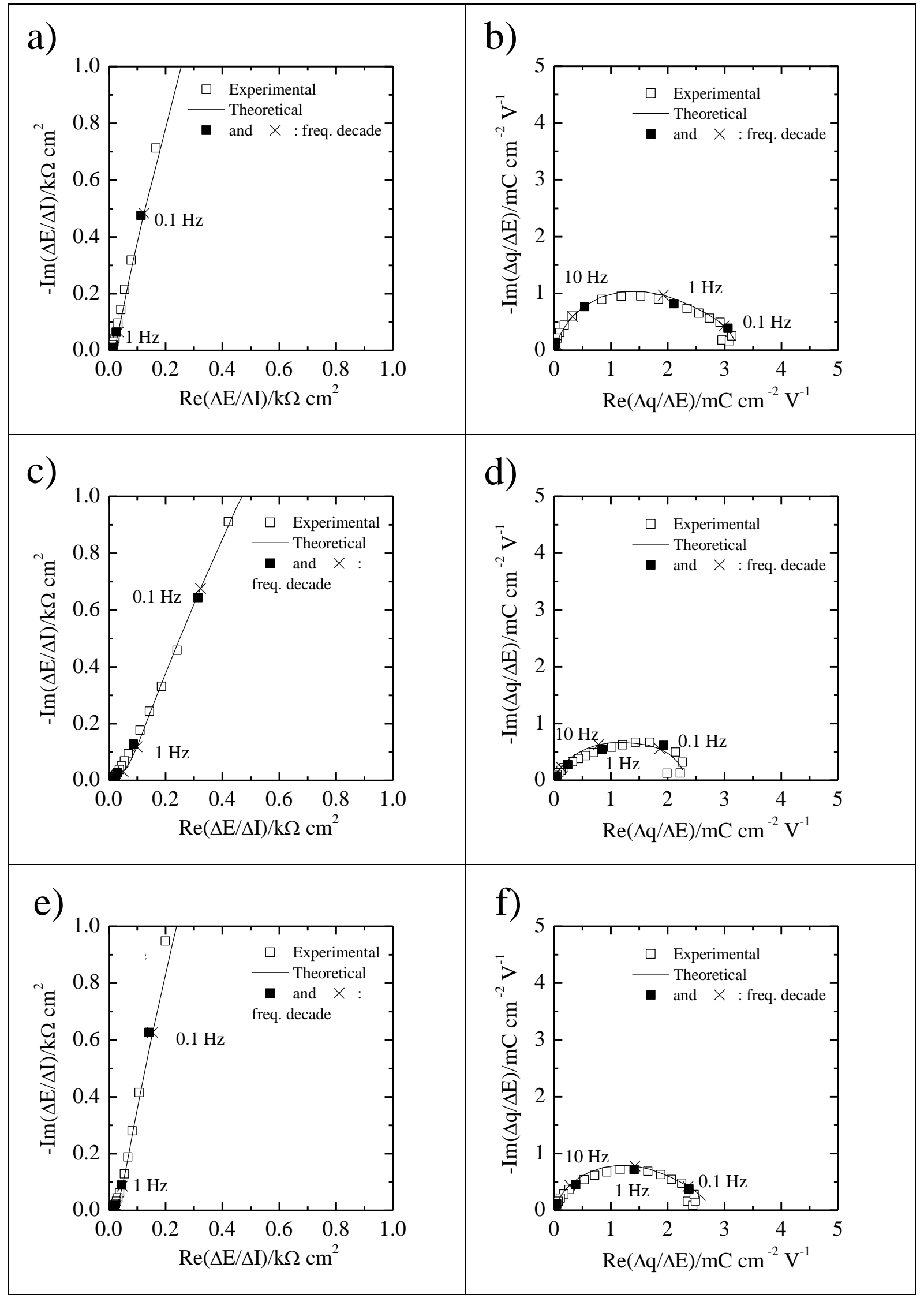


Figure 7: Measured and simulated transfer functions $\frac{\Delta E}{\Delta I}(\omega)$ and $\frac{\Delta q}{\Delta E}(\omega)$ of the PPy-DS (a and b), PPy-DS/CeO 2 NPs $\left(2\right.$ g.dm ${ }^{-3}$ ) (c and d) and PPy-DS/CeO 2 NPs $\left(5\right.$ g.dm ${ }^{-3}$ ) (e and f) films at $-1 V$ vs. SSE in 0.5 mol. $\mathrm{dm}^{-3} \mathrm{NaCl}$ aqueous electrolyte. The film thickness is 200 $\mathrm{nm}$ and the parameters used for the calculations are given in Table I. 


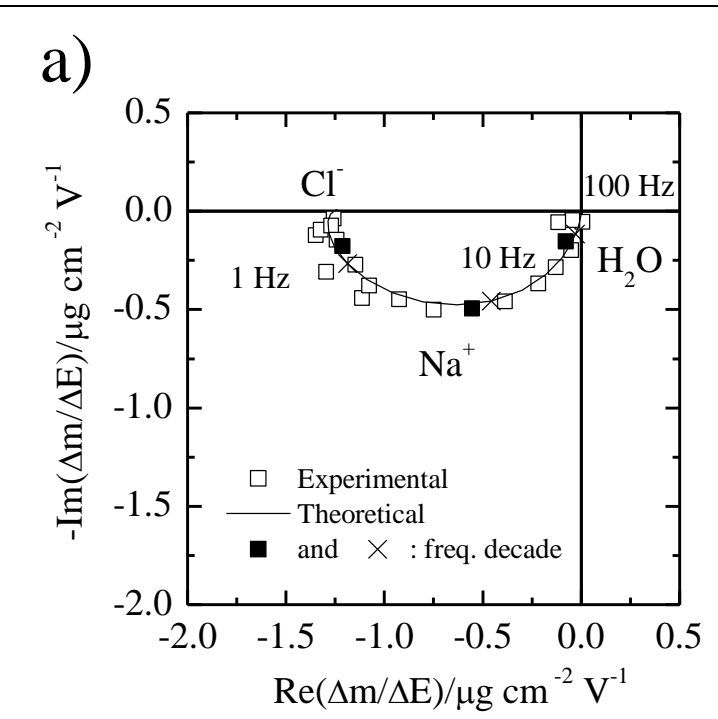

b)

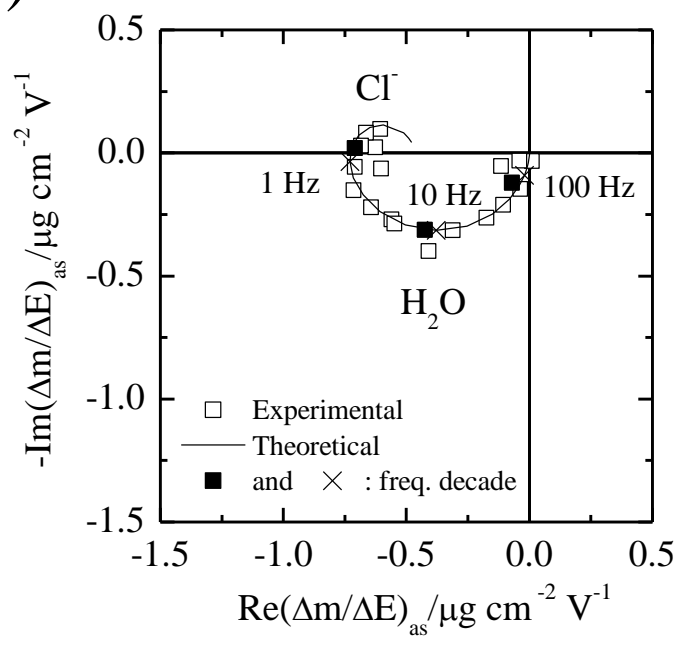

c)

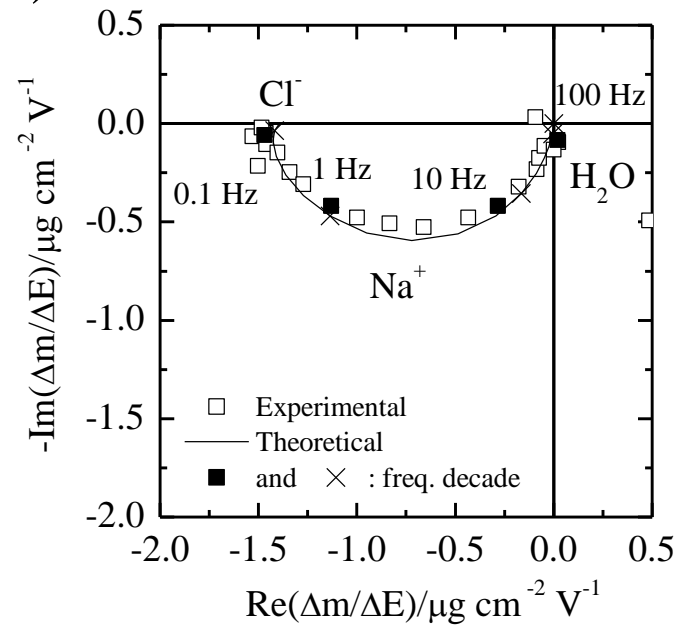

d)

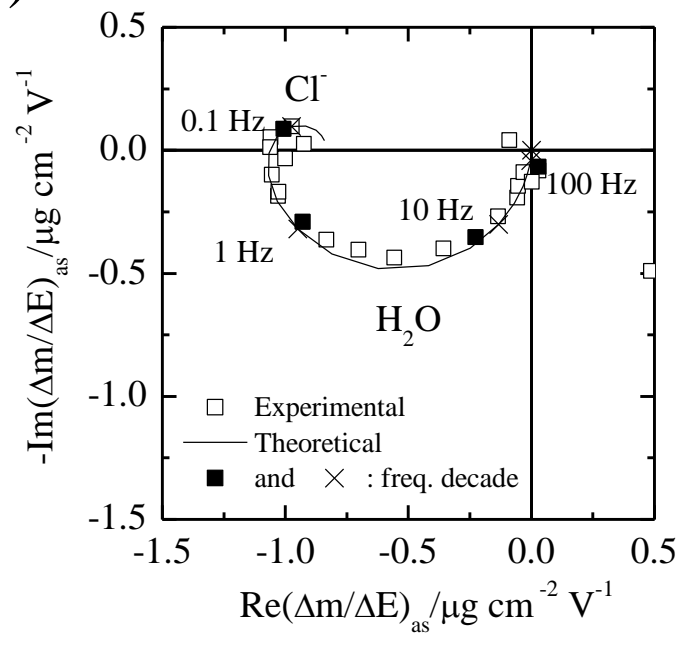

e)

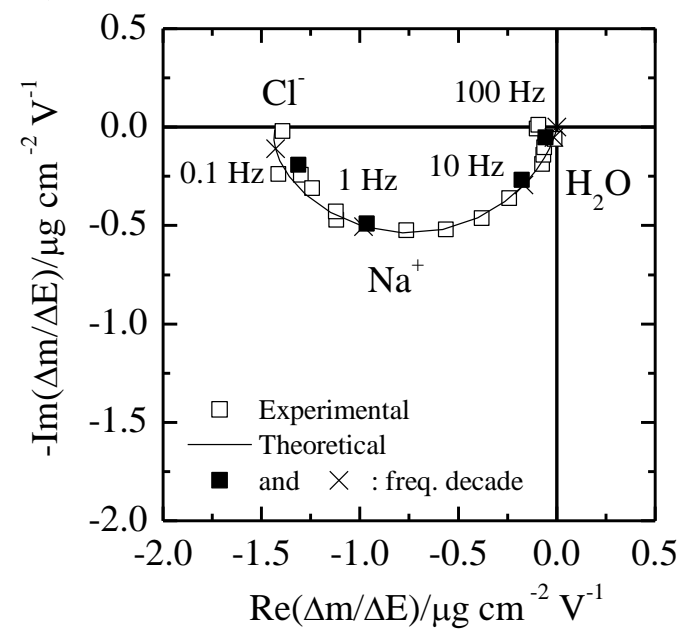

f)

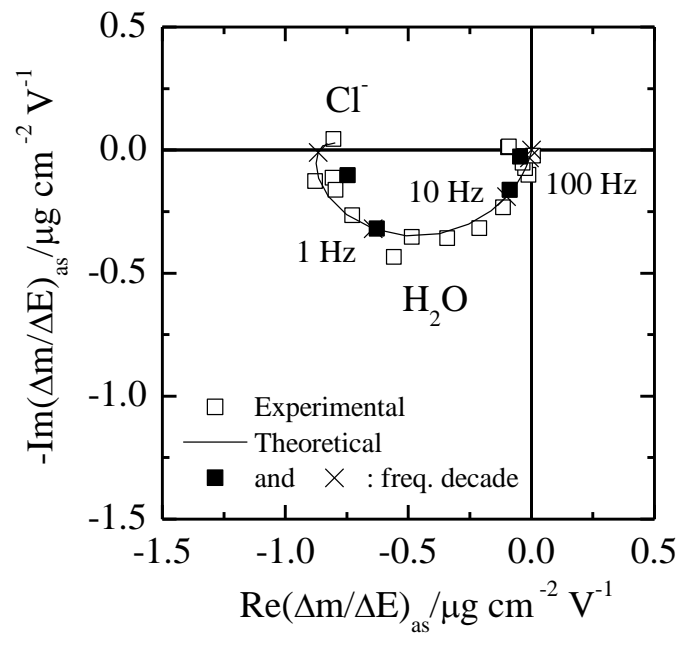


Figure 8: Measured and estimated mass transfer functions, $\frac{\Delta m}{\Delta E}(\omega)$, and partial anionsolvent transfer functions of the PPy-DS (a and b), PPy-DS/CeO $\mathrm{NPs}_{2}\left(2 \mathrm{~g} \cdot \mathrm{dm}^{-3}\right)$ (c and d) and PPy-DS/CeO 2 NPs $\left(5\right.$ g.dm ${ }^{-3}$ ) (e and f) films at $-1 V$ vs. SSE in 0.5 mol.dm ${ }^{-3} \mathrm{NaCl}$ aqueous electrolyte. The film thickness is $200 \mathrm{~nm}$ and the molar mass of the species involved in the charge compensation as follows: $\mathrm{m}\left(\mathrm{Na}^{+}\right)=23 \mathrm{~g} \cdot \mathrm{mol}^{-1}, \mathrm{~m}\left(\mathrm{Cl}^{-}\right)=35.5 \mathrm{~g} \cdot \mathrm{mol}^{-}$ $\left.{ }^{1}, \mathrm{~m}\left(\mathrm{H}_{2} \mathrm{O}\right)=18 \mathrm{~g} \cdot \mathrm{mol}^{-1}\right)$. The parameters used for the calculations are given in Table I. 
a)

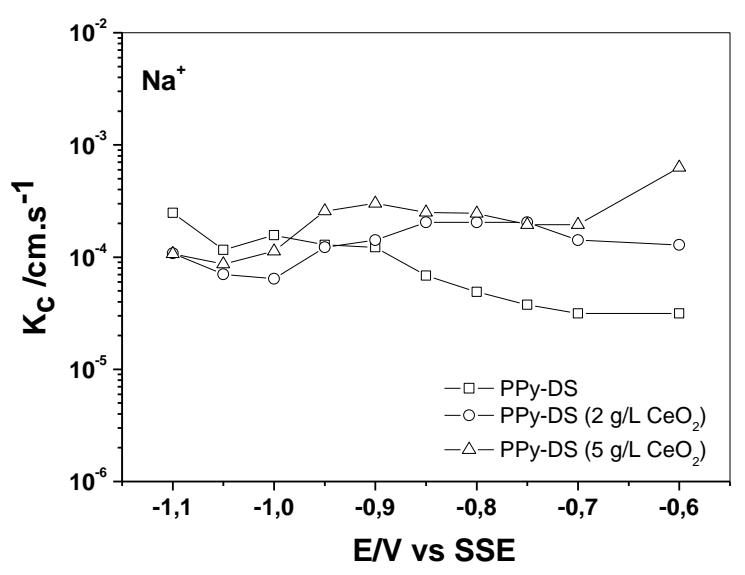

b)

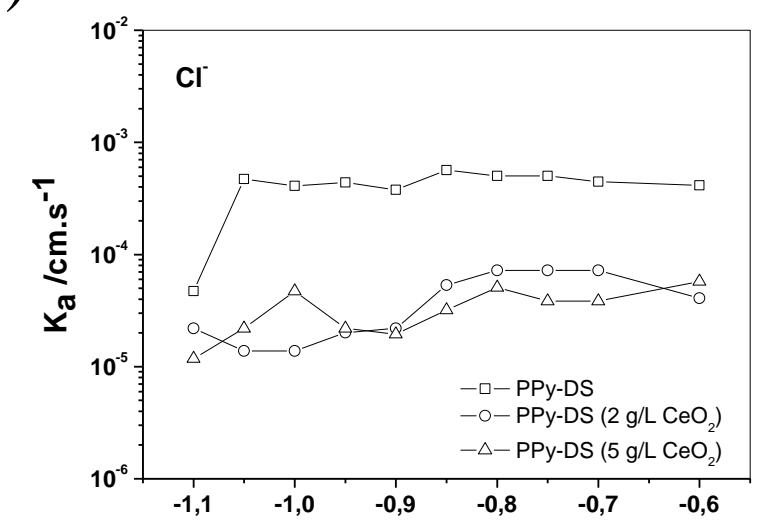

c)

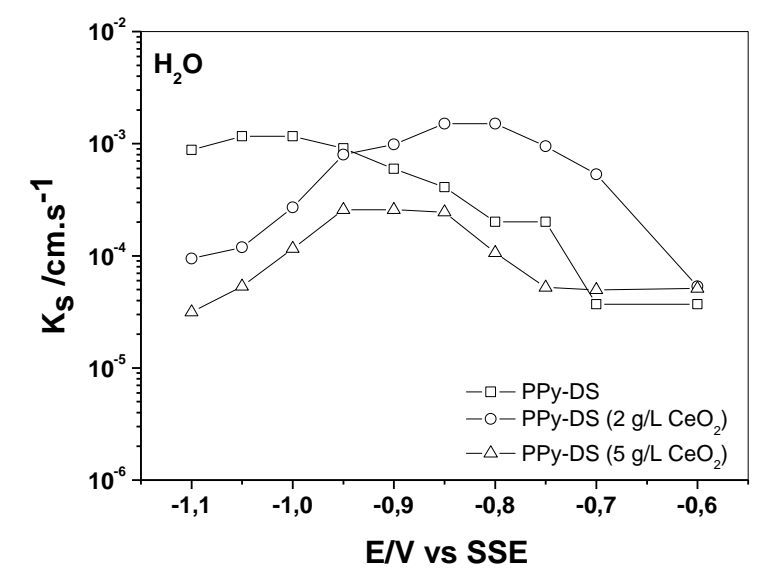

d)

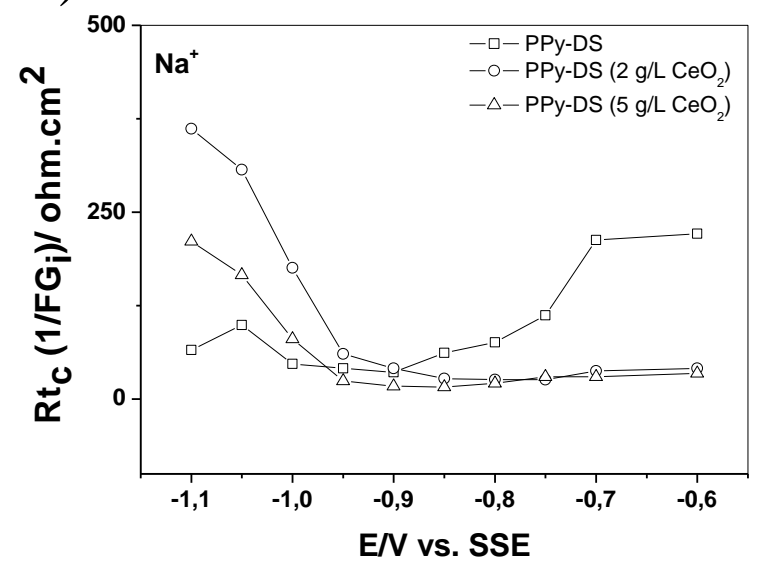

e)

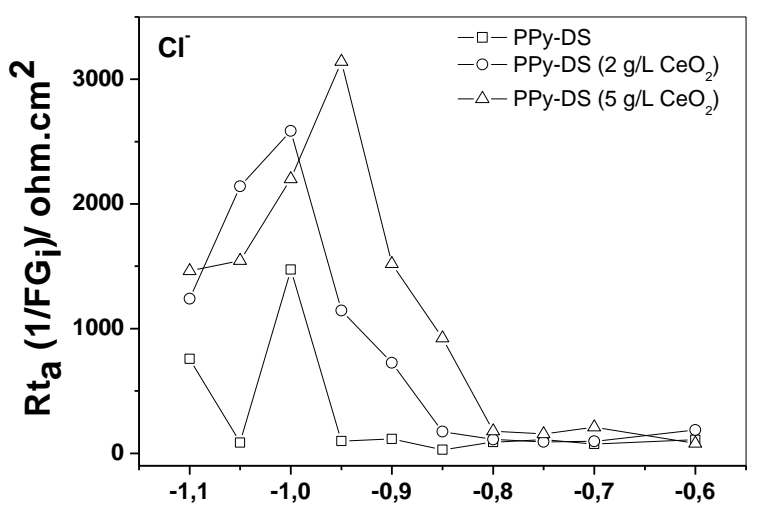

f)

E/V vs. SSE

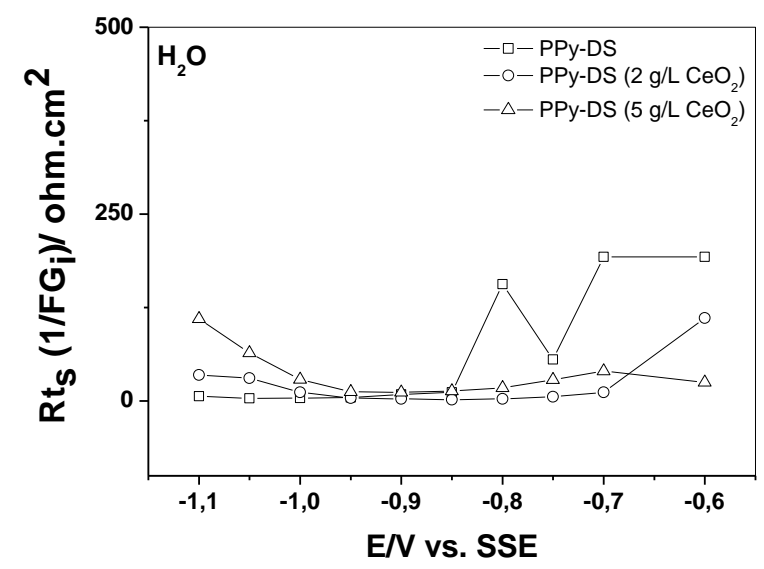

Figure 9: Estimated values for the kinetic parameters a-c) $K_{i}$ and d-f) $\mathrm{Rt}_{\mathrm{i}}=\frac{1}{\mathrm{FG}_{\mathrm{i}}} / \Omega . \mathrm{cm}^{2}$ as a function of potential for the PPy-DS, PPy-DS/CeO ${ }_{2} \mathrm{NPs}\left(2 \mathrm{~g} \cdot \mathrm{dm}^{-3}\right)$ and PPy-DS/CeO NPs $\left(5 \mathrm{~g} . \mathrm{dm}^{-3}\right)$ films. 
a)

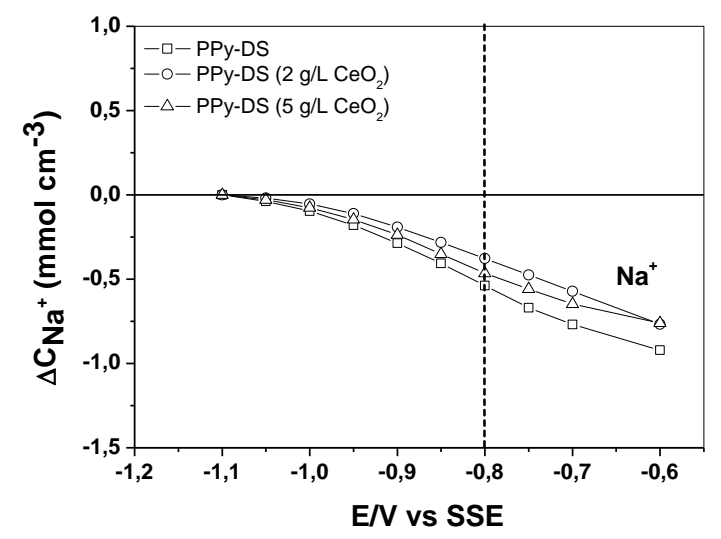

b)

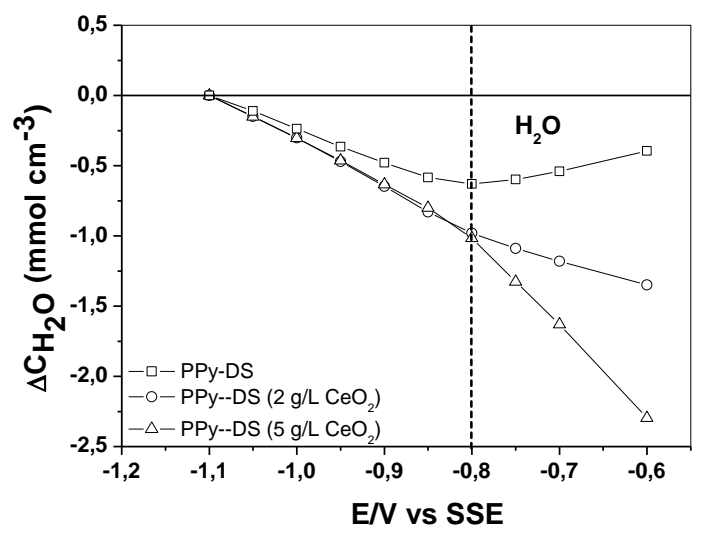

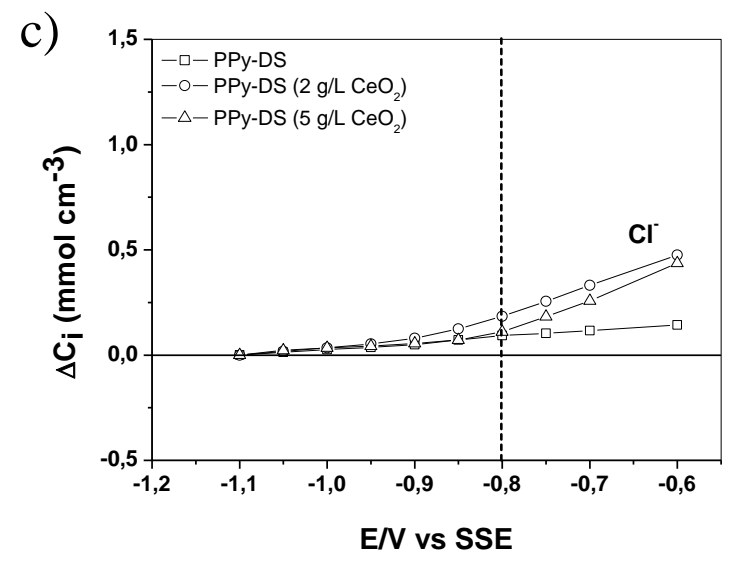

Figure 10: Relative concentration change, $\Delta C_{i}$, for a) $\mathrm{Na}^{+}$, b) $\mathrm{H}_{2} \mathrm{O}$, and c) $\mathrm{Cl}^{-}$of the $\mathrm{PPy}-$ DS, PPy-DS/CeO ${ }_{2}$ NPs $\left(2\right.$ g.dm $\left.{ }^{-3}\right)$ and PPy-DS/CeO 2 NPs $\left(5\right.$ g.dm $\left.{ }^{-3}\right)$ films as a function of the applied potential in $0.5 \mathrm{~mol} . \mathrm{dm}^{-3} \mathrm{NaCl}$ aqueous electrolyte. 


\begin{tabular}{|c|c|c|c|c|}
\hline $\mathrm{CeO}_{2}$ samples & $\mathrm{A}\left(\mathrm{m}^{2} / \mathrm{g}\right)$ & $\mathrm{d}_{\mathrm{BET}}(\mathrm{nm})$ & $\mathrm{d}_{\mathrm{XRD}}(\mathrm{nm})$ & $\mathrm{d}_{\text {TEM }}(\mathrm{nm})$ \\
\hline $\mathrm{a}$ & - & - & 43 & $60 \pm 40^{*}$ \\
$\mathrm{~b}$ & 62 & 13 & 13 & $15 \pm 2$ \\
$\mathrm{c}$ & 84 & 10 & 9 & $10 \pm 1$ \\
$\mathrm{~d}$ & 70 & 12 & 10 & $12 \pm 1$ \\
\hline
\end{tabular}

Table 1: Crystallite size values obtained by BET, XRD and TEM. (*size distribution for this sample is very large, from $20 \mathrm{~nm}$ to $300 \mathrm{~nm}$, as deduced from the exploitation of Figure 3a). 
Table 2: Estimated values for $\mathrm{K}_{\mathrm{i}}, \mathrm{Rt}_{\mathrm{i}}$ and $-\mathrm{G}_{\mathrm{i}} / \mathrm{K}_{\mathrm{i}}$ parameters from ac-electrogravimetry measurements/simulations in $0.5 \mathrm{~mol} . \mathrm{dm}^{-3} \mathrm{NaCl}$ at $-1 \mathrm{~V} v$ s. SSE for the three tested films.

\begin{tabular}{|c|c|c|c|c|c|c|c|c|c|}
\hline -1 V vS. SSE & \multicolumn{3}{|c|}{$\mathrm{K}_{\mathrm{i}} \times 10^{5} / \mathrm{cm} \cdot \mathrm{s}^{-1}$} & \multicolumn{3}{|c|}{$\mathrm{Rt}_{\mathrm{i}}=\frac{1}{\mathrm{FG}_{\mathrm{i}}} / \Omega \cdot \mathrm{cm}^{2}$} & \multicolumn{3}{|c|}{$\begin{array}{c}\left.\frac{\Delta \mathrm{C}_{\mathrm{i}}}{\Delta \mathrm{E}}\right)_{\omega \rightarrow 0}=-\frac{\mathrm{G}_{\mathrm{i}}}{\mathrm{K}_{\mathrm{i}}} / \\
\mathrm{mmol} \cdot \mathrm{cm}^{-3} \cdot \mathrm{V}^{-1}\end{array}$} \\
\hline $\begin{array}{c}\text { Ions - } \\
\text { solvent }\end{array}$ & $\mathrm{Na}^{+}$ & $\mathrm{Cl}^{-}$ & $\mathbf{H}_{2} \mathbf{O}$ & $\mathbf{N a}^{+}$ & $\mathrm{Cl}^{-}$ & $\mathrm{H}_{2} \mathrm{O}$ & $\mathrm{Na}^{+}$ & $\mathrm{Cl}^{-}$ & $\mathrm{H}_{2} \mathrm{O}$ \\
\hline PPy-DS & 15.7 & 2.5 & 116.0 & 47.1 & \begin{tabular}{|l|}
1473.0 \\
\end{tabular} & 4.0 & 1.4 & 0.3 & 2.1 \\
\hline $\begin{array}{l}\text { PPy-DS / } \\
\mathrm{CeO}_{2} \mathrm{NPs} \\
\left(2 \mathrm{~g} \cdot \mathrm{dm}^{-3}\right) \\
\end{array}$ & 6.4 & 1.4 & 27.0 & 175.7 & 2585.0 & 11.8 & 0.9 & 0.3 & 3.2 \\
\hline $\begin{array}{l}\text { PPy-DS / } \\
\mathrm{CeO}_{2} \mathrm{NPs} \\
(5 \text { g.dm }\end{array}$ & 11.3 & 1.5 & 11.6 & 80.3 & 2200.0 & 28.7 & 1.1 & 0.3 & 3.1 \\
\hline
\end{tabular}

